\title{
Flexural testing and analysis of full-strain-fields in sandwich composites
}

\author{
R. Marat-Mendes \\ Escola Superior Náutica Infante D. Henrique, Av. Eng. Bonneville Franco, 2770-058, Paço de Arcos, Portugal \\ IDMEC, Instituto Superior Técnico, Universidade de Lisboa, Av. Rovisco Pais, 1, 1049-001 Lisboa, Portugal \\ CDP2T, Escola Superior de Tecnologia de Setúbal, Campus do IPS, Estefanilha, 2914-508 Setúbal, Portugal \\ rosamarat@enautica.pt, https:/ /orcid.org/0000-0002-3435-8241
}

\section{R. Martins}

Instituto Superior Técnico, Universidade de Lisboa, Av. Rovisco Pais, 1, 1049-001 Lisboa, Portugal

ricardosomartins@gmail.com

\section{A. Garcia}

Instituto Superior Técnico, Universidade de Lisboa, Av. Rovisco Pais, 1, 1049-001 Lisboa, Portugal

alexandre.garcia@ist.utl.pt

\section{Reis}

IDMEC, Instituto Superior Técnico, Universidade de Lisboa, Av. Rovisco Pais, 1, 1049-001 Lisboa, Portugal luis.g.reis@tecnico.ulisboa.pt, bttps://orcid.org/0000-0001-9848-9569

\begin{abstract}
The objective of this work was to characterize the full-field flexural behavior of composite sandwich beams. Finite element analysis was used to estimate the behavior of sandwich beams under three- and four-pointbending tests and were compared with experimental results obtained via digital image correlation and strain-gauges. Two different polyurethane core thicknesses and two different sandwich lengths were used to simulate shortand long-beam. Two distinct sandwich beams were used by means of two different faces: aluminum and basalt fiber reinforced polymer composite. Fullstrain-fields and flexural displacements results were obtained showing that BFRP sandwiches exhibited higher flexibility and higher capacity of absorption energy than the aluminum specimens however with a higher prospect of core shear failure. For both face materials short-beams present higher strains than the long-beams and $4 \mathrm{~PB}$ test specimens showed negative strain distribution in the upper side of the specimen and positive in the underside contrary to $3 \mathrm{~PB}$ that presents positive strain distribution along the
\end{abstract}

Citation: Marat-Mendes, R., Martins, R., Garcia, A., Reis, L., Flexural testing and analysis of full-strain-fields in sandwich composites, Frattura ed Integrità Strutturale, 49 (2019) 568-585.

Received: 26.02 .2019

Accepted: 20.06 .2019

Published: 01.07.2019

Copyright: (C) 2019 This is an open access article under the terms of the CC-BY 4.0, which permits unrestricted use, distribution, and reproduction in any medium, provided the original author and source are credited. 
fulfilled. Moreover, results show that the strain distribution in not symmetric. Obtained experimental results are in good agreement with estimations; the digital image technique attested to be a complementary method to strain gages measurements in experimental full-strain-fields analysis.

KEYwORDs. Composite sandwich beams; strain-fields; FEM; DIC; VIC; strain-gages.

\section{INTRODUCTION}

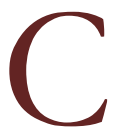

omposite sandwich structures have in recent years found well-known acceptance in advanced structural applications mainly because of their high strength and lightweight characteristics. A sandwich structure typically requires two flat or lightly profiled thin, stiff and strong face sheets separated by a thicker, lighter and weaker core. The strong and stiff thin faces provide flexural capacity and stiffness of the sandwich while the low density and thick core with proper shear strength and stiffness transfers shear stresses between the two faces [1]. The faces and the core are bonded to obtain effective stress transfer between the elements. The face sheet is typically made of metal or fiber reinforced plastics, while a low-density honeycomb or foam are chosen for the core. Among the non-metallic materials the composites are the generally employed, because of its high elasticity while improves weight-bending stiffness. One of these fascinating materials with extraordinary properties is the basalt fiber that is a novel kind of inorganic fiber manufactured from the extrusion of melted basalt rock and is commercially available. The basalt fiber reinforced polymer (BFRP) composites exhibits excellent properties such as high strength, high elastic module and corrosion resistance [2]. The manufacturing process of basalt fibers although quite similar to the glass-fiber, do not use additives resulting in a decrease in production costs and environmental impact [3][4].

Sandwich composite structures may be subjected to several loading situations, such as impacts or large flexural loadings resulting in various failure modes including core compression failure, debonding between facing and core, deflection of interfacial crack into the core and buckling instability. When subjected to flexural bending, the faces store the main part of the external bending moment as in-plane stresses while the core carries the transverse forces as shear stress and stabilizes the faces against bucking or wrinkling [5].

Several standard test methods for evaluation of core shear properties are available in the literature, as the single-block shear test standard [6] and the 3PB (three-point bending) and 4PB (four-point bending) standards [7]. However, the flexural behavior of composite sandwich structures is very complex and standard methods for determining deflections on beams and strains in both skin and core, such as displacement transducers and strain-gages, are not sufficient for estimating the stress-strain-full-field behavior of these components. Some authors showed these difficulties [8][9][10], such as de Freitas et al. [10] in a study of renovation of orthotropic steel bridge decks using sandwich structures made by two steel faces and a polyurethane core and also Reis et al. [11][12], studied the mechanical behavior of sandwich beam using cork as core and showed that the failure occurs mainly in the core.

Recent progress in full-field measurement techniques, in particular, digital image correlation (DIC)[13], enables additional flexibility for assessment of stress-strain constitutive properties for composite materials, compared to conventional straingages. Strain-fields gradients can be evaluated and the specimen dimension restrictions to achieve uniform strain distributions in the strain gage section can be eliminated [14]. Several authors have studied and implemented the DIC technique in their works. Cintrón et al. has obtained relations between some of the most important variables involved in the digital image correlation and produced a simple tutorial for the setup and operation of the equipment [15]. Yang et al. [16] have tested several materials and concluded that DIC can measure true strain at any point in the specimen, while the average strain should be obtained with the traditional methods. Fergusson et al. [17] showed that the DSP provides meaningful strain measurement for composite sandwich structures and further work is needed. Thus, displacements and strain-full-field determination across and through sandwich panels is necessary and more studies are deemed necessary.

Digital image correlation (DIC) system using VIC system of Correlated Solutions was used in this work to measure the deformation and strain-full-fields of composite sandwich structures subjected to bending tests. DIC results were compared and validated with finite element analysis, analytical and strain-gages data. 


\section{Experimental Procedure}

\section{Materials}

wo distinct sandwich composite materials were manufactured in this study via two different face materials: Aluminum plates and basalt fiber reinforced polymer composites (BFRP). The sandwich core was attained with polyurethane plates with two different thicknesses, $h_{\mathfrak{c}},(20 \mathrm{~mm}$ and $30 \mathrm{~mm})$ enabling a wider range of tests and results to be analyzed. The composite matrix material was prepared at room-temperature by mixing the epoxy resin SR1500 with the corresponding curing hardener SD2505 (both from Sicomin ${ }^{\circledR}$ ) in a 100:33 weight ratio, according to supplier instructions. A woven basalt fiber fabric Basalte $x^{\circledR}$ TM BAS 220.1270.T containing twill $2 / 2$ basalt fibers with 0.13 mm thickness was used as reinforcement in the prepared samples. The main properties of the plain materials used in this work are presented in Tab. 1. The material properties were obtained by suppliers, except the polyurethane core that was experimentally obtained according to ASTM C365 [18] using a standard test method for flatwise compressive strength of sandwich cores.

\begin{tabular}{cccccc}
\hline & $\begin{array}{c}\text { Density } \\
{\left[\mathrm{kg} / \mathrm{m}^{3}\right]}\end{array}$ & $\begin{array}{c}\text { Young's } \\
\text { Modulus }[\mathrm{MPa}]\end{array}$ & $\begin{array}{c}\text { Poisson } \\
\text { Ratio }\end{array}$ & $\begin{array}{c}\text { Shear Modulus } \\
{[\mathrm{MPa}]}\end{array}$ & $\begin{array}{c}\text { Thickness } \\
{[\mathrm{mm}]}\end{array}$ \\
Aluminum 2024 & 2780 & 73000 & 0.33 & 28000 & $h_{f}=1$ \\
Polyurethane* & 40 & 9.2 & 0.33 & 3.46 & $h_{c}=20$ \\
SikeaForce-7710L100 & 1520 & 0.013 & 0.33 & - & $h_{c}=30$ \\
Resin SR1500 + SD2505 & 1.0 & 3.2 & 0.26 & - & - \\
Basalt (twill) 220.1270.T & 2.8 & 78 & 0.35 & - & 0.13 \\
\hline
\end{tabular}

Table 1: Material properties of raw material (as mentioned by suppliers, except when referred*).

\section{Preparation of the sandwich composites}

Two different sandwich composites were manufactured by means of two face materials: aluminum face sandwich composites named $S A$; and BFRP face sandwich composites named $S B$. The sandwich composites were produced via different methods, as explained in the next sections.

\section{SA - Sandwich composites with aluminum faces}

The sandwich composites with aluminum faces were prepared by cutting individually the polyurethane and the aluminum plates into rectangular sections $(390 \mathrm{~mm} \times 70 \mathrm{~mm}$ ) (Fig. 1 (a)) and then cleaned, polished and removed any irregularity or impurity to ensure a good adhesion between the aluminum faces and the polyurethane core. SikaForce ${ }^{\circledR}-7710$ L100 was used as an adhesive and $5 \mathrm{~kg}$ of weigh for 24 hours was applied to bond the aluminum faces to the core. Prior to gluing the SikaForce ${ }^{\circledR}$ components were mixed in the $4: 1$ by volume ratio to form a homogeneous blend, according to supplier instructions.

\section{SB - Sandwich composites with BFRP faces}

The sandwich composites with BFRP faces followed standard procedures for the mixture and homogenization of epoxy resin and hardener (33 wt \%) formulations. Vacuum bag hand lay-up technique was used to produce the fiber-reinforced composites faces. The procedure consisted on the alternate placement of basalt fabric and resin layers with lay-up $[(0 / 90) /(45 /-45)]_{\mathrm{s}}$ on each side of the polyurethane core. Contrary to that for aluminum specimens, the cores of the BFRP specimens were manufactured in groups of three specimens, with a clearance that allowed the composite edges to be removed. This way, six polyurethane plates with $430 \mathrm{~mm} \times 260 \mathrm{~mm}$ where placed between the BFRP faces (Fig. 1 (b)) and were manufactured according to ASTMC273 [6], ASTMC274 [19], ASTMC393 [7], ASTMD7249 [20] standards.

Porous Teflon film and peel-ply film were placed above the completed stack. To ensure uniform thickness and good surface quality of the samples, steel plates were placed above and below of the absorbent felt (Fig. 2 (a)). The whole assembly was kept under primary vacuum $(850 \mathrm{mPa}$ ) and allowed to cure during $48 \mathrm{~h}$ at room temperature (Fig. 2 (b)). Thus, plates with rectangular sections $(430 \mathrm{~mm} \times 780 \mathrm{~mm}$ ) were cut into $390 \mathrm{~mm}$ x $70 \mathrm{~mm}$ specimens with a diamond circular saw. The main properties of the BFRP composite faces used in this work are presented in Tab. 2. 

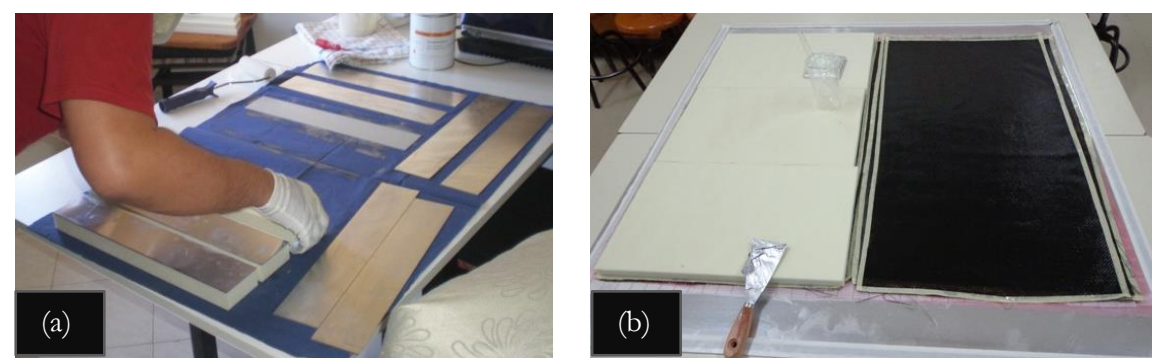

Figure 1: Manufacturing of the sandwiches with: (a) aluminum skins; (b) BFRP skins.
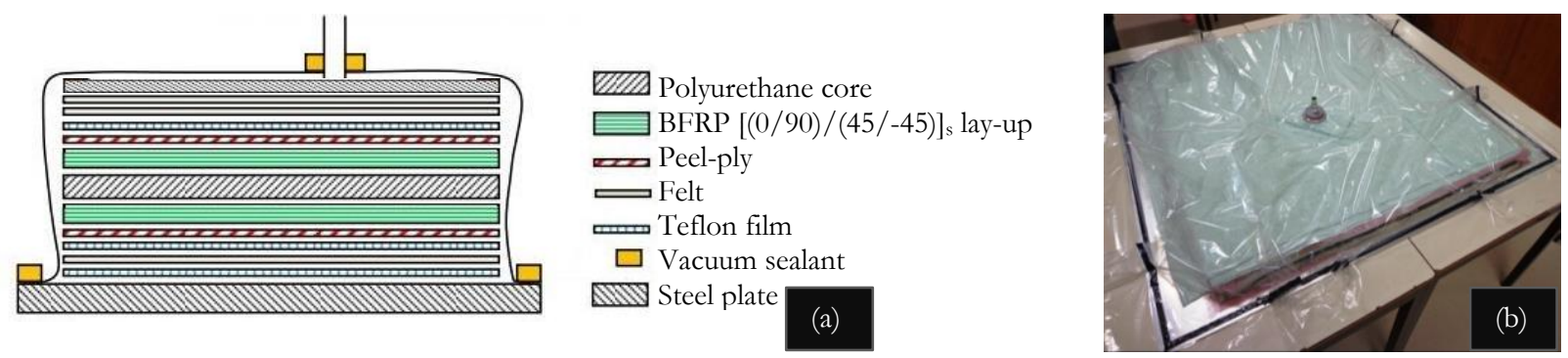

Figure 2: Manufacturing of the SB sandwich composites: (a) Stacking sequence before vacuum bagging; (b) Vacuum bag.

\begin{tabular}{cccccccc}
\hline & $\begin{array}{c}\text { Density } \\
{\left[\mathrm{kg} / \mathrm{m}^{3}\right]}\end{array}$ & $\begin{array}{c}E_{11}=E_{22} \\
{[\mathrm{GPa}]}\end{array}$ & $\begin{array}{c}E_{33} \\
{[\mathrm{GPa}]}\end{array}$ & $v_{12}=v_{13}$ & $v_{23}$ & $\begin{array}{c}G_{12}=G_{13}=G_{23} \\
{[\mathrm{GPa}]}\end{array}$ & $\begin{array}{c}\text { Thickness } \\
{[\mathrm{mm}]}\end{array}$ \\
$\begin{array}{c}\text { BFRP } \\
\text { composite }\end{array}$ & 1538 & 16 & 3.2 & 0.33 & 0.35 & 2.7 & $h_{f}=1$ \\
\hline
\end{tabular}

Table 2: BFRP Properties. (1, 2, 3 refers to longitudinal, transversal and across the thickness of the specimens, respectively)
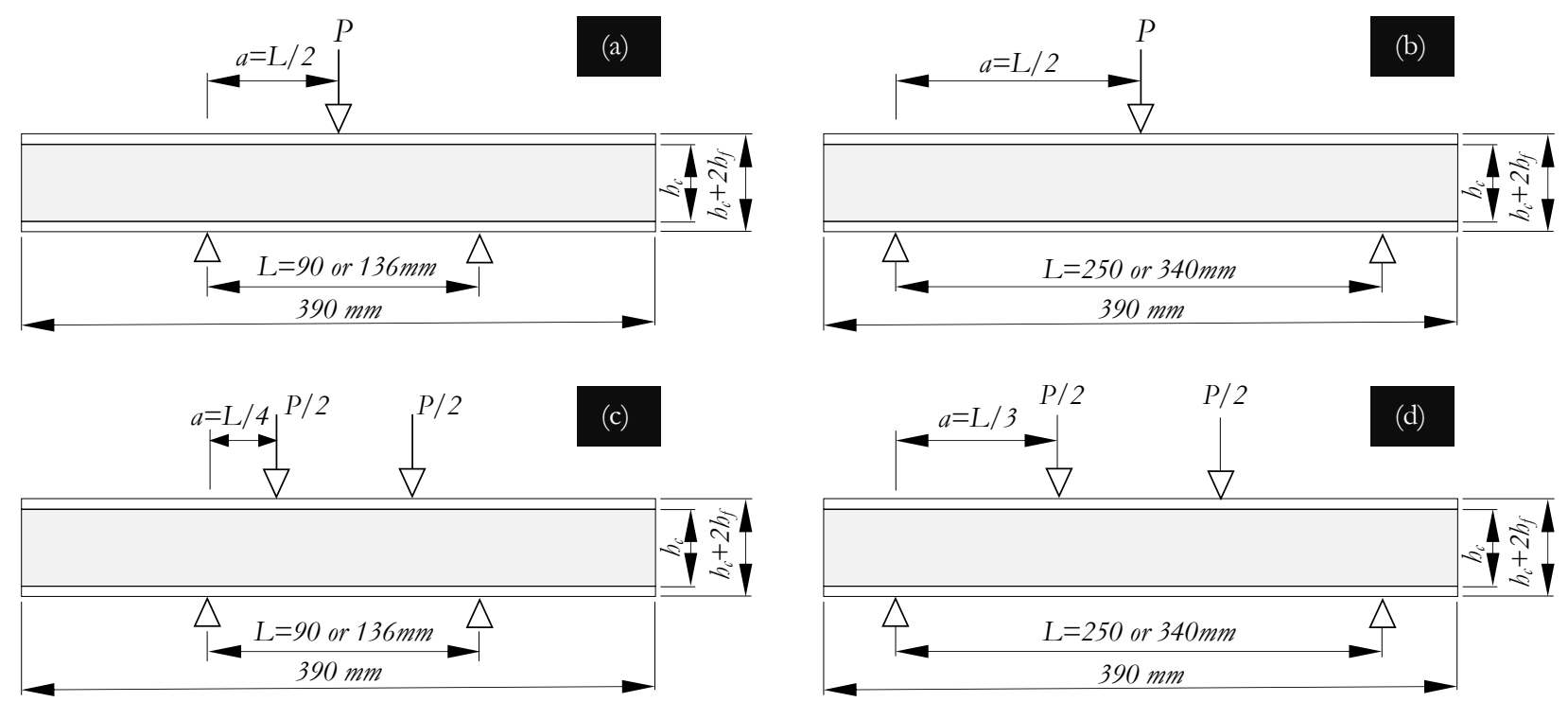

Figure 3: Schematic diagram of the test field configuration for the specimens' with: (a) 3PB short-beam; (b) 3PB long-beam; (c) 4PB short-beam; (d) 4PB long-beam. (all specimens have the same width, $b=70 \mathrm{~mm}$, perpendicular to the paper)

\section{Mechanical Testing}

Mechanical tests were undertaken in an Instron3369 universal test machine equipped with a $10 \mathrm{kN}$ load cell. Three-point bending (3PB) and four-point bending (4PB) flexural tests were conducted in conformity to ASTMC393 [7] with a crosshead rate of $2 \mathrm{~mm} / \mathrm{min}$. Prior to mechanical tests, strain gages were glued to the surfaces of the 3PB (bottom) and 4PB (top and bottom) specimens in order to obtain the strains in the sandwich composite faces. 
To induce short- and long-beam on both 3PB and 4PB tests, span lengths of: 90, 136, 250 and $340 \mathrm{~mm}$ with 20 or $30 \mathrm{~mm}$ core thickness specimens were adopted. Fig. 3 (a) and Fig. 3 (b) illustrates schematic diagrams of test specimens' geometries under $3 \mathrm{~PB}$ in short- and long-beam respectively. In 4PB tests, short- and long-beam were induced with the application of a quarter and a third span length as shown in Fig. 3 (c) and Fig. 3 (d) in that order. At least three samples of each condition were tested for reproducibility assessment totalizing 48 mechanical tests. Load-displacement plots were obtained for all conditions in order to obtain the linear and the non-linear outliner to apprehend the flexural deformation and the stressstrains in the linear region and also the fracture behavior that occurs in the various test conditions.

An encoding was created based on the assignment of characters: $S A$ (sandwich composites with aluminum faces) or $S B$ (sandwich composites with BFRP faces); followed by the length relation short or long; the load condition of the test under $3 P B$ or $4 P B$ and at last the core thickness $(20$ and 30$)$. The various tested specimens' dimensions and encoding are shown in Tab. 3.

\begin{tabular}{ccccc}
\hline$h_{c}(\mathrm{~mm})$ & $d(\mathrm{~mm})$ & $L(\mathrm{~mm})$ & $a(\mathrm{~mm})$ & Specimens' name \\
20.0 & 22.0 & 90.0 & 45.0 & $S A$ or $S B \_s h o r t 3 P B \_20$ \\
30.0 & 32.0 & 136.0 & 68.0 & $S A$ or $S B \_s h o r t 3 P B \_30$ \\
20.0 & 22.0 & 250.0 & 125.0 & $S A$ or $S B \_l o n g \_3 P B \_20$ \\
30.0 & 32.0 & 340.0 & 170.0 & $S A$ or $S B \_l o n g \_3 P B \_30$ \\
\hline 20.0 & 22.0 & 90.0 & 22.5 & $S A$ or $S B \_s h o r t 4 P B \_20$ \\
30.0 & 32.0 & 136.0 & 34.0 & $S A$ or $S B \_s h o r t 4 P B \_30$ \\
20.0 & 22.0 & 250.0 & 83.3 & $S A$ or $S B \_l o n g \_4 P B \_20$ \\
30.0 & 32.0 & 340.0 & 113.3 & $S A$ or $S B \_l o n g \_4 P B \_30$ \\
\hline
\end{tabular}

Table 3: Specimens' dimensions and encoding. ( $b_{c}-$ core thickness; $d$ - total thickness $\left(d=b_{c}+2 h_{f}\right) ; L-$ span length; $a-$ shear span $)$

\section{Digital Image Correlation}

The Correlated Solutions VIC system is a Digital Image Correlation (DIC) technique, which is defined as a method to measure the deformations of a surface by comparing images, thus allowing data to be obtained without any interaction with the material [15][16][17][21]. This aspect of non-interaction with the analyzed material is especially relevant because it ensures that errors are not introduced per se in the test, such as the case of strain gages applied into porous and low stiffness foam cores that can lead to a local increase of stiffness and thus measure non-representative strains. The system consists basically on one or two cameras (respectively, $2 \mathrm{D}$ or $3 \mathrm{D}$ analysis) that capture the images during the experimental test and by a computer software that renders the correlation [15][16].
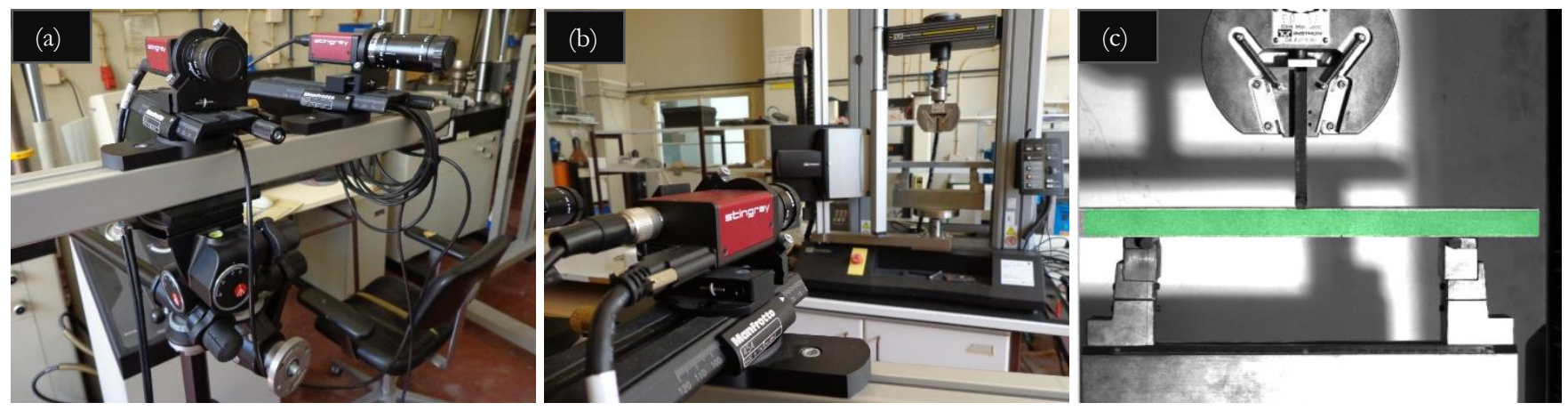

Figure 4: Digital Image Correlation with VIC2D system: (a) Cameras installation; (b) Image capturing (c) AOI.

In this work, VIC2D solution has been used to obtain the strain-fields inner the specimens. Prior to DIC technique, the surfaces of the specimens were coated with a thin layer of white acrylic paint. Using an airbrush, carbon black paint was sprayed over the white surfaces, creating random black and white artificial speckle pattern. After that, the longitudinal section of the specimen was defined as an Area Of Interest (AOI) and the values of 21 and 5 were assigned for the subset 
and for the step, respectively (defining the mesh to be analyzed) [22][23]. The camera that captures the images was placed perfectly aligned with the specimen and perpendicular to the surface to be analyzed (Fig. 4 (a) and Fig. 4 (b)), to be able to capture the entire AOI to be studied (Fig. 4 (c)). In the end of the analysis, the computer software provides the information about displacements in $x$ and $y$ directions, through a color gradient representing ranges of displacement or other selected variables. Sequences of images were collected as the displacement control progresses from 1, 2 and $3 \mathrm{~mm}$. The images collected during the experiments were then processed using VIC2D system to estimate displacements and strain-fields along the specimen's width.

\section{THEORETICAL AND FEM ANALYSIS}

\section{Beam theory for Sandwich panels}

T $\mathrm{n}$ this section it is outlined the elastic flexural analysis of sandwich beams under $3 \mathrm{~PB}$ and $4 \mathrm{~PB}$ loads that includes the measurement of mid-span-length displacements and normal stresses. Deflection under 3PB and 4PB tests can be calculated analytically by Eqn. (1) and Eqn. (2), sandwich bending stiffness by Eqn. (3) and shear rigidity by Eqn. (4) in conformity to ASTM C393 [7]

$$
\begin{aligned}
& \Delta_{3 P B}=\frac{P L^{3}}{48 D}+\frac{P L}{4 L} \\
& \Delta_{4 P B}=\frac{11 P L^{3}}{768 D}+\frac{P L}{8 U} \\
& D=\frac{E\left(d^{3}-h_{c}{ }^{3}\right) b}{12} \\
& U=\frac{G\left(d+h_{c}\right)^{2} b}{4 c}
\end{aligned}
$$

where $P$ referring to applied load, $L$ to span length, $D$ to panel bending stiffness, $U$ to panel shear rigidity, $b$ to sandwich width, $h_{c}$ to core thickness, $d$ to sandwich thickness $\left(d=h_{c}+2 h_{f}\right)$ where $h_{f}$ refers to skin thickness, $E$ to facing modulus and $G$ to core shear modulus. The load introduced in Eqns. (1) and (2) were the loads obtained experimentally by loaddisplacements mechanical tests.

The facing bending stress (mid-span load) can be also estimated by Eqns. (5) and (6) for 3PB and 4PB, respectively [7]:

$$
\begin{gathered}
\sigma=\frac{P L}{2 h_{f}\left(d+h_{c}\right) b} \\
\sigma=\frac{P L}{4 h_{f}\left(d+h_{c}\right) b}
\end{gathered}
$$

\section{Finite Element Modelling}

3D solid finite element analysis (FEA) was implemented using the commercial code according to Siemens NX10 in order to obtain the displacements and strain-fields to validate the experimental results, obtained by VIC2D system, strain gages and also analytically.

The development of a finite element analysis was divided into three distinct steps: Creation of a computer-aided design model (CAD) of the geometry of the structure to be studied; Creation of a finite element model (FEM), where the structure to be analyzed was discretized; and Creation of a simulation model, where boundary constraints and loads were applied, performing the finite element analysis (FEA).

The first step in the development of the finite element model was the creation of a CAD pattern of the specimen with 390 $\mathrm{mm}$ long, $70 \mathrm{~mm}$ wide, $1 \mathrm{~mm}$ thick for the faces (aluminum and basalt) and 20 or $30 \mathrm{~mm}$ for the core. In addition, halfcylinders were modeled to simulate the rollers and supports of the crosshead testing machine, which were modeled with 10 $\mathrm{mm}$ for the diameter and $70 \mathrm{~mm}$ in length and positioned according to the span and type of test to be analyzed. Fig. 5 (a) exemplifies a model of a $3 \mathrm{~PB}$ test with $30 \mathrm{~mm}$ of core thickness and $340 \mathrm{~mm}$ of span length inducing a long-beam specimen. 

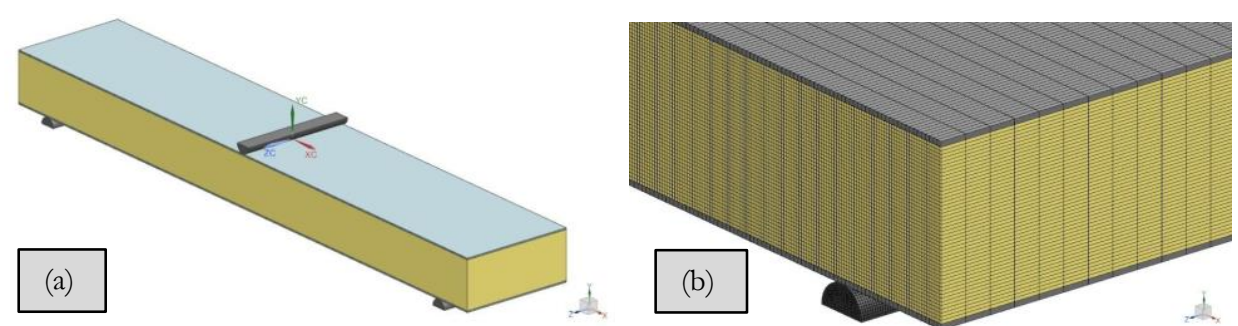

Figure 5: Finite element modelling; (a) CAD model of a 3PB long-beam specimen; (b) Detail of the FEM with uniform distribution is assumed in the faces (grey), the core (yellow) and half-cylinders (dark grey).

3D Collector elements were applied defining for each component the physical properties on the FEM: for the aluminum faces, polyurethane core and half-cylinders' PSOLID properties were chosen; for the BFRP faces SOLID LAMINATE property was select, specifying the basalt fiber fabric lay-up. 8-node hexahedral solid-body elements $C H E X A$ were used. These elements use a reduced integration and a BUBBLE function (NX10 internal function) in order to control the shear locking that appears in solid elements when subjected to flexure and shear [24]. The polyurethane core and the faces (aluminum and BFRP) were modeled with $5 \mathrm{~mm}$ of element size in the width. For mutually thickness and length directions an element size of $1 \mathrm{~mm}$ and $0.625 \mathrm{~mm}$ for the faces and for the core were adopted respectively. The skin dimension of $1 \mathrm{~mm}$ was chosen because in the basalt faces it is important that the thickness of the element corresponds to the total thickness of the stacking used in SOLID LAMINATE [25]. The half-cylinders were modeled with a $0.5 \mathrm{~mm}$ element in all directions. A detail of the FEM is present in Fig. 5(b) showing the uniform distribution of the elements in the core, faces and half-cylinders.

In the FEA, the analysis solution, the boundary conditions, the applied loads and the solution parameters were defined. It was elected a SOL101 Linear Statics to perform the analysis solution due to aiming to analyze the linear elastic region of the specimens. The boundary conditions were applied on the half-cylinders and the bonded connection between the faces and the core was modeled with the SURFACE-TO-SURFACE GLUING command, while the contact between the half cylinders and the faces was modeled by the command SURFACE-TO-SURFACE CONTACT. The two surfaces in contact were paired, taking into consideration to choose the most refined surface as the origin (half-cylinders) and the surface less refined as the target (faces) in order to obtain the maximum contact points [26]. After gluing the surfaces, it was defined a WELD LIKE CONNECTION with a penalty factor. This penalty factor represents the Young's Modulus of the adhesive, and it was assumed $13 \mathrm{~Pa}$ (Young's Modulus of the SikaForce-7710 L100) for the SA specimens and $3200 \mathrm{MPa}$ (Young's Modulus of the Resin SR1500+SD2505 matrix) for the SB specimens [27].

Boundary conditions were applied on both half-cylinders and specimen. The underneath half-cylinders were considered fixed while the upper ones were constrained in all degrees of freedom except in the vertical direction $\left(\mathrm{u}_{\mathrm{y}}=\right.$ free). Constraints were also applied into the nodes that are in contact between the underneath of the specimen and the supports (Fig. 6). Loads were applied into the upper-half-cylinders. The applied loads were obtained from the experimental load-displacement plots in the linear elastic region, i.e. from 1, 2 and $3 \mathrm{~mm}$ of cross-head displacement control.

Fig. 6 shows an example of a 4PB test specimen with the applied loads and boundary conditions. In order to make easy the visualization, the mesh and boundary conditions applied to supports were not plotted.

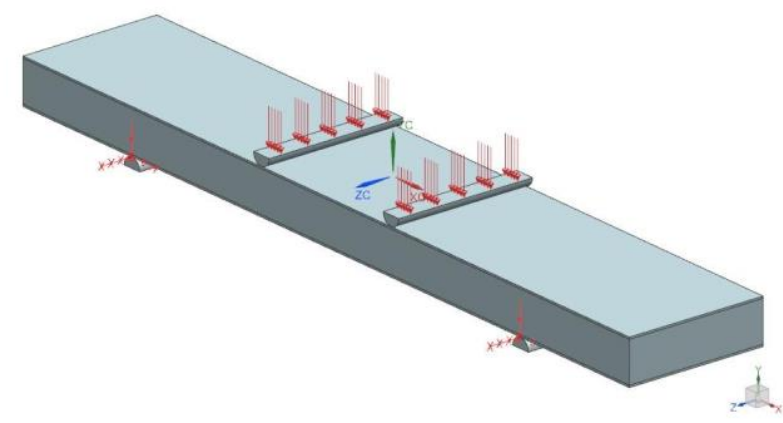

Figure 6: Example of boundary conditions on a 4PB test specimen.

Regarding the solution parameters, an iterative process was defined, and the displacements, stresses and strains were defined as outputs. This process was chosen due to software recommendation when using 3D solid elements. 


\section{RESULTS}

\section{Flexural Behavior of Sandwich Structures}

7 he load-displacement data of the sandwiches were recorded during the bending tests and Fig. 7 shows the representative flexural curves for all previously described conditions in Tab. 3. The load-displacement plots exhibited an initial linear elastic region with a subsequent non-linear part resulted in the decrease of the slope near to the maximum load (elasto-plastic phase). This phenomenon can be visualized in all 3PB test specimens (Fig. 7 (a)). In practically all $4 \mathrm{~PB}$ essay it could not be possible to obtain the maximum load in the non-linear region (Fig. 7 (b)), however when it was possible, these tests present higher maximum load than the 3PB. This phenomenon is due to the lower midspan maximum displacement achieved by these specimens indicating higher bending stiffness comparing to $3 \mathrm{~PB}$ as can be verified by Tab. 4 and Fig. 8 .

Tab. 4 and Fig. 8 shows the effect of: load condition (3PB or 4PB); core thickness (20 or 30mm); face material (SA or SB) and sandwich length (short- or long-beam) on the mid-span compliance and bending stiffness of sandwich composites. It is also reported the span-to-depth a/d ratio which denotes the short- $(a / d<3)$ and long-beam $(a / d>3)$. It is evident that the core thickness increase (20 to $30 \mathrm{~mm}$ ) led to a decrease of the equivalent bending stiffness, however in general the maximum load increase indicates an augment of the maximum stress (Fig. 7 and Fig. 8). Regardless of the face material, aluminum sandwich structures showed higher maximum load and higher bending stiffness (Fig. 7 and Fig. 8) than BFRP faces for all test conditions. This difference is more evident in the short-beam with $4 \mathrm{~PB}$ tests presenting $49 \%$ higher stiffens. Longbeams showed a decrease on the bending stiffness and on the maximum flexural load indicating a higher flexural deformation. Tab. 4 also summarizes the visually observed failure modes that occur in the sandwich beams after tested and explained further ahead.

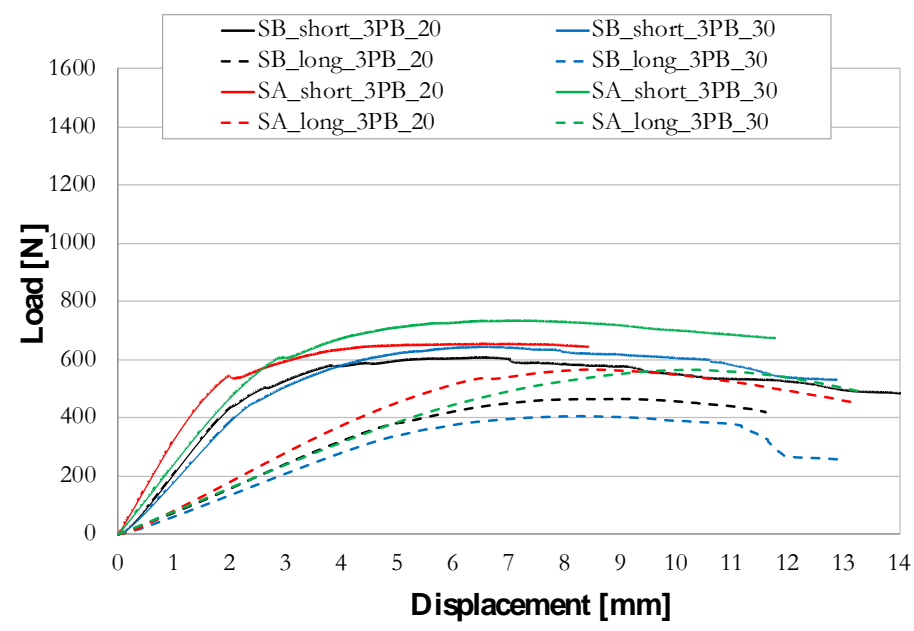

a)

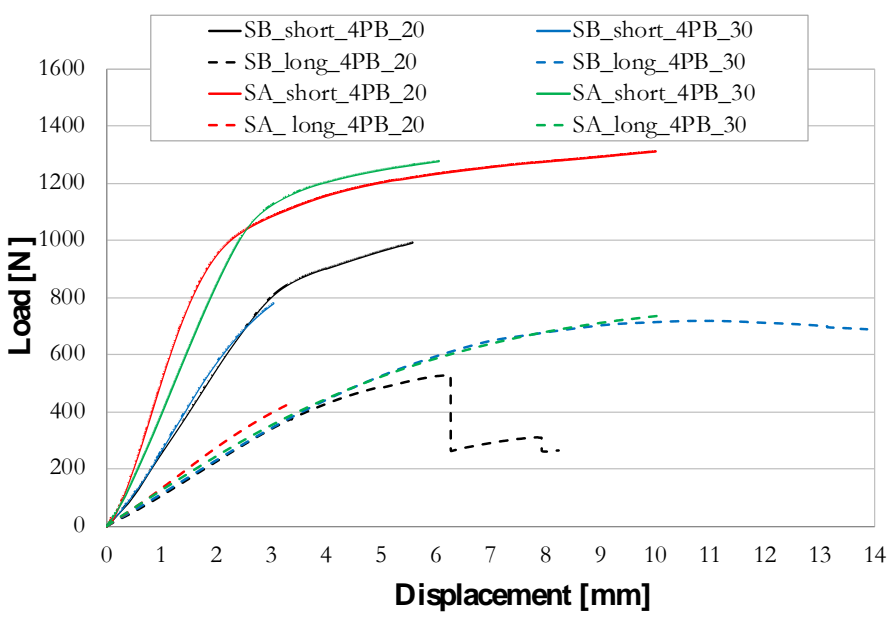

b)

Figure 7: Load-displacement plots of sandwiches for short- and long-beam condition containing both core thickness (20 and $30 \mathrm{~mm}$ ) and for both face materials (SA and SB) under: (a) 3PB tests; (b) 4PB tests. 


\begin{tabular}{ccc}
\hline Specimen & $a / d$ & Observed failure mode \\
SA_short_4PB_20 & $1.0 \approx 1$ & indentation \\
SA_short_4PB_30 & $1.1 \approx 1$ & skin-to-core bond failure \\
SA_short_3PB_20 & $2.0 \approx 2$ & without elastic recovery \\
SA_short_3PB_30 & $2.1 \approx 2$ & \\
\hline SA_long_4PB_20 & $3.8 \approx 4$ & indentation \\
SA_long_4PB_30 & $3.5 \approx 4$ & core shear failure \\
SA_long_3PB_20 & $5.6 \approx 5$ & skin-to-core bond failure \\
SA_long_3PB_30 & $5.3 \approx 5$ & without elastic recovery \\
\hline SB_short_4PB_20 & $1.0 \approx 1$ & core shear failure \\
SB_short_4PB_30 & $1.1 \approx 1$ & face crushing \\
SB_short_3PB_20 & $2.0 \approx 2$ & skin-to-core bond failure \\
SB_short_3PB_30 & $2.1 \approx 2$ & with elastic recovery \\
\hline SB_long_4PB_20 & $3.8 \approx 4$ & core shear failure \\
SB_long_4PB_30 & $3.5 \approx 4$ & face crushing \\
SB_long_3PB_20 & $5.6 \approx 5$ & skin-to-core bond failure \\
SB_long_3PB_30 & $5.3 \approx 5$ & with elastic recovery \\
\hline
\end{tabular}

Table 4: Span to total thickness ratio and observed failure modes of Sandwich composites ( $S A$-aluminum faces; $S B$-BFRP faces. 20 or 30-referes to core thickness).

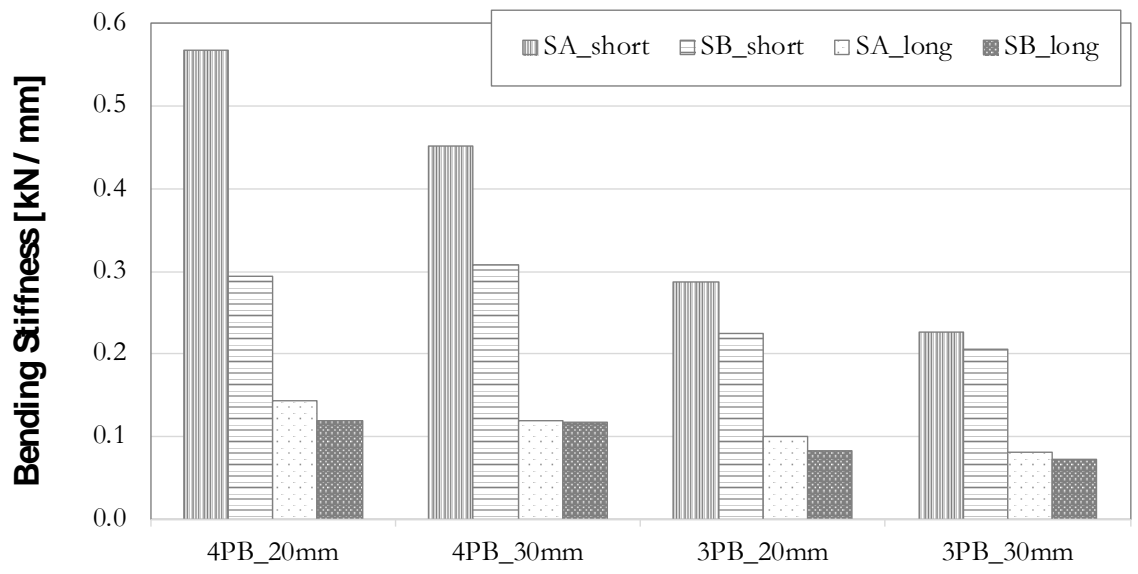

Figure 8: Bending stiffness of the sandwich composites.

Analyzing Fig. 8 it is clear that the bending stiffness decreases when comparing 4PB with 3PB tests, 20 with 30mm core thickness and short- with long-beams. The $S A$ specimens present an average decrease of $41 \% \pm 11 \%$ between the $4 \mathrm{~PB}$ and $3 \mathrm{~PB}$ specimen while $S B$ samples shows a decrease of $31 \% \pm 6 \%$. Regarding the specimen's thickness it is also visible even less evident, especially for the $S B$, that the bending stiffness decreases from the 20 to $30 \mathrm{~mm}$ specimens in an average of $19 \% \pm 2 \%$ for the $S A$ and $4 \% \pm 7 \%$ for the $S B$. The highest difference is detected between the short and long-beam bending stiffness presenting a $70 \% \pm 6 \%$ of reduction for the $S A$ and $62 \% \pm 2 \%$ for the $S B$ specimens. The bending stiffness reduction between aluminum $(S A)$ and BFRP $(S B)$ faces are more evident for the short-beam presenting a reduction of $28 \%$ $\pm 17 \%$ meanwhile for the long-beam the reduction has an average of $11 \% \pm 8 \%$.

Fig. 9 and Fig. 10 exhibits the failure behavior that occurs in all tested specimens. It is distinct that in all $S A$ specimens (Fig. 9(a), Fig. 9(b), Fig. 10(a) and Fig. 10(b)), delamination between aluminum faces and core in both top and central bottom of the specimens occurs due to skin-to-core bond failure due to the large deformations occurred, mainly because of the higher indentation that occurs in $S A$ than in the $S B$ specimens. This can be also caused by the technique used in the manufacture 
of the specimens, once the aluminum faces are glued to the core with Sika-force $\mathbb{R}$ glue, while the BFRP composite faces are bonded to the core by means of the same epoxy resin with which the faces are hand-lay-up, inducing higher diversity in the mechanical properties of the adhesive/face bond in the $S A$ specimens than in the $S B$.

The lower indentation in the $S B$ tests is because of the higher flexibility and higher capacity of absorption energy of this material. This phenomenon is evident comparing Fig. 9 (a) with Fig. 9 (c) and Fig. 10 (a) with Fig. 10 (c). In fact, after SB specimens' tests, these ones recover practically its original form indicating an enormous elastic recovery, visually exhibiting only face crushing in the indentation points (Fig. 9 (d)) hiding inner core failure. The higher flexibility of the $S B$ specimens causes higher prospect of core shear failure on both 3PB and 4PB tests, as shown in Fig. 9 (c), Fig. 10 (c) and Fig. 10 (d). However, this shear core effect also affects the $S$ A_long specimens. The visually observed failure modes that occur in the sandwich beams after tested are summarized in Tab. 4.
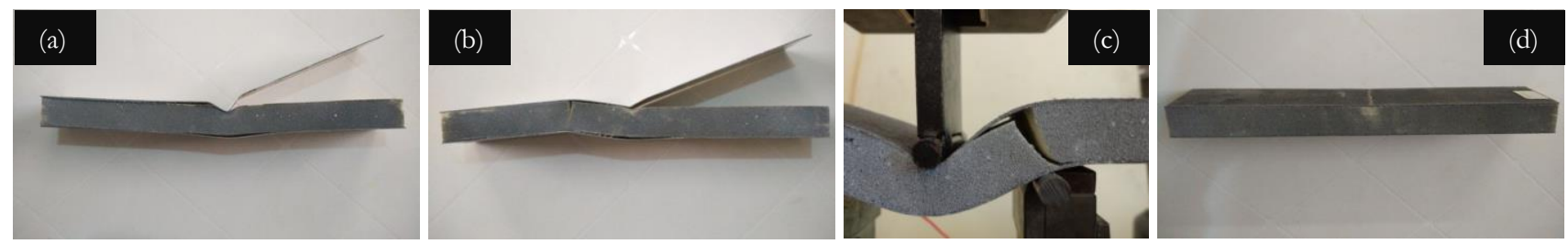

Figure 9: Failure behavior of sandwiches under 3PB tests: (a) $S A \_$short_3PB; (b) $S A \_l o n g \_3 P B$; (c) SB_short_3PB; (d) $S B \_l o n g 3 P B$.
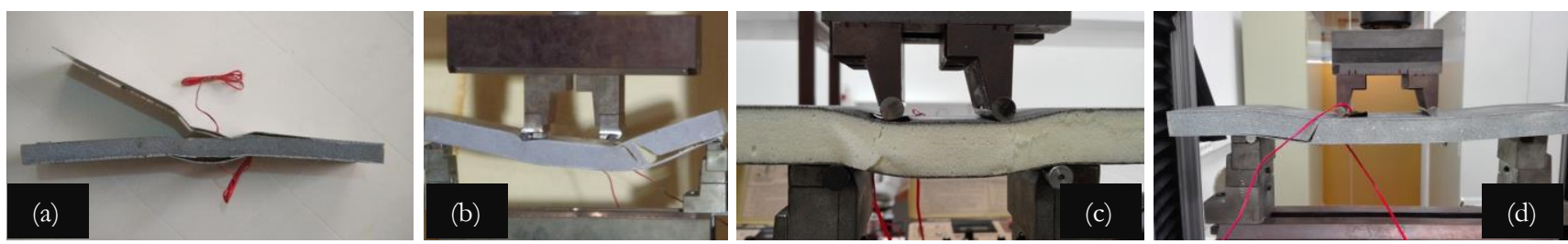

Figure 10: Failure behavior of sandwiches under 4PB tests: (a) $S A \_s h o r t 4 P B$; (b) $S A \_l o n g \_4 P B$; (c) SB_short_4PB; (d) SB_long_4PB.

\begin{tabular}{|c|c|c|c|c|c|c|c|c|c|c|c|}
\hline \multirow{2}{*}{$\begin{array}{l}\text { Load } \\
\text { (N) }\end{array}$} & \multicolumn{3}{|c|}{ Stress $(M P a)$} & \multirow{2}{*}{$\begin{array}{c}\text { Rel. Error } \\
\text { sup. }(\%)\end{array}$} & \multirow{2}{*}{$\begin{array}{c}\text { Rel. Error } \\
\text { inf. }(\%)\end{array}$} & \multirow{2}{*}{$\begin{array}{l}\text { Load } \\
\text { (N) }\end{array}$} & \multicolumn{3}{|c|}{ Stress $(M P a)$} & \multirow{2}{*}{$\begin{array}{c}\text { Rel. Error } \\
\text { sup. (\%) }\end{array}$} & \multirow{2}{*}{$\begin{array}{l}\text { Rel. Error } \\
\text { inf. }(\%)\end{array}$} \\
\hline & Ana. & FE $A$ sup. & FEA inf. & & & & Ana. & FE $A$ sup. & FEA inf. & & \\
\hline \multicolumn{6}{|c|}{ SA_short_3PB_20 } & \multicolumn{6}{|c|}{ SB_short_3PB_20 } \\
\hline 296.7 & 4.541 & -3.007 & 3.225 & $34 \%$ & $29 \%$ & 208.8 & 3.196 & -2.832 & 2.817 & $11 \%$ & $12 \%$ \\
\hline 583.1 & 8.925 & -5.911 & 6.338 & $34 \%$ & $29 \%$ & 434.4 & 6.649 & -5.746 & 5.855 & $14 \%$ & $12 \%$ \\
\hline 671.8 & 10.283 & -6.810 & 7.302 & $34 \%$ & $29 \%$ & 528.2 & 8.085 & -6.988 & 7.121 & $14 \%$ & $12 \%$ \\
\hline \multicolumn{6}{|c|}{ SA_short_3PB_30 } & \multicolumn{6}{|c|}{ SB_short_3PB_30 } \\
\hline 243.4 & 3.814 & -3.075 & 3.134 & $19 \%$ & $18 \%$ & 181.1 & 2.838 & -2.601 & 2.564 & $8 \%$ & $10 \%$ \\
\hline 469.2 & 7.352 & -5.819 & 6.042 & $21 \%$ & $18 \%$ & 386.8 & 6.060 & -5.556 & 5.476 & $8 \%$ & $10 \%$ \\
\hline 608.1 & 9.528 & -7.542 & 7.830 & $21 \%$ & $18 \%$ & 507.8 & 7.956 & -7.294 & 7.188 & $8 \%$ & $10 \%$ \\
\hline \multicolumn{6}{|c|}{ SA_long_3PB_20 } & \multicolumn{6}{|c|}{ SB_long_3PB_20 } \\
\hline 78.4 & 3.333 & -2.932 & 2.958 & $12 \%$ & $11 \%$ & 72.8 & 3.095 & -2.611 & 2.605 & $16 \%$ & $16 \%$ \\
\hline 178.0 & 7.568 & -6.656 & 6.716 & $12 \%$ & $11 \%$ & 154.6 & 6.573 & -5.545 & 5.535 & $16 \%$ & $16 \%$ \\
\hline 275.7 & 11.722 & -10.309 & 10.403 & $12 \%$ & $11 \%$ & 239.2 & $\begin{array}{c}10.17 \\
0\end{array}$ & -8.579 & 8.563 & $16 \%$ & $16 \%$ \\
\hline \multicolumn{6}{|c|}{ SA_long_3PB_30 } & \multicolumn{6}{|c|}{ SB_long_3PB_30 } \\
\hline 77.9 & 3.051 & -2.800 & 2.815 & $8 \%$ & $8 \%$ & 60.7 & 2.378 & -2.294 & 2.279 & $4 \%$ & $4 \%$ \\
\hline 158.4 & 6.205 & -5.693 & 5.724 & $8 \%$ & $8 \%$ & 133.7 & 5.237 & -5.054 & 5.020 & $3 \%$ & $4 \%$ \\
\hline 239.0 & 9.362 & -8.590 & 8.636 & $8 \%$ & $8 \%$ & 208.4 & 8.163 & -7.877 & 7.825 & $4 \%$ & $4 \%$ \\
\hline
\end{tabular}

Table 5: Analytical and FEA mid-span facing bending stress for the 3PB specimens. 


\section{Mid-span bending Stress behavior}

Analytical and FEA mid-span bending stress behavior was analyzed using loads obtained experimentally by loaddisplacements plots from the three distinct linear elastic displacement control: 1, 2 and $3 \mathrm{~mm}$, i.e. from these three displacements, three forces were attained, and the analytical bending stresses arisen from Eqns. (5) and (6) were correlated with the FEA ones.

Tab. 5 and Tab. 6 presents the mid-span facing bending stress obtained by the 3PB and 4PB specimens, respectively. The FEA take into account the variation of the vertical displacement along the thickness unlike the analytical method, so upper and below stresses (FEA sup., FE $A$ inf.) are present and compared with the analytical.

\begin{tabular}{|c|c|c|c|c|c|c|c|c|c|c|c|}
\hline \multirow{2}{*}{$\begin{array}{l}\text { Load } \\
\text { (N) }\end{array}$} & \multicolumn{3}{|c|}{ Stress $(\mathrm{MPa})$} & \multirow{2}{*}{$\begin{array}{c}\text { Rel. Error } \\
\text { sup. (\%) }\end{array}$} & \multirow{2}{*}{$\begin{array}{c}\text { Rel. } \\
\text { Error } \\
\text { inf. }(\%)\end{array}$} & \multirow{2}{*}{$\begin{array}{l}\text { Load } \\
\text { (N) }\end{array}$} & \multicolumn{3}{|c|}{ Stress (MPa) } & \multirow{2}{*}{$\begin{array}{c}\text { Rel. Error } \\
\text { sup. }(\%)\end{array}$} & \multirow{2}{*}{$\begin{array}{c}\text { Rel. Error } \\
\text { inf. }(\%)\end{array}$} \\
\hline & Ana. & FEA sup. & FE $A$ inf. & & & & Ana. & FEA sup. & FEA inf. & & \\
\hline \multicolumn{6}{|c|}{ SA_short_4PB_20 } & \multicolumn{6}{|c|}{ SB_short_4PB_20 } \\
\hline 510.4 & 3.906 & -3.135 & 3.669 & $20 \%$ & $6 \%$ & 413.0 & 3.161 & -2.879 & 3.245 & $9 \%$ & $3 \%$ \\
\hline 949.9 & 7.270 & -5.838 & 6.832 & $20 \%$ & $6 \%$ & 640.0 & 4.898 & -4.461 & 5.028 & $9 \%$ & $3 \%$ \\
\hline 1084.9 & 8.303 & -6.667 & 7.803 & $20 \%$ & $6 \%$ & 755.0 & 5.778 & -5.253 & 5.921 & $9 \%$ & $2 \%$ \\
\hline \multicolumn{6}{|c|}{ SA_short_4PB_30 } & \multicolumn{6}{|c|}{ SB_short_4PB_30 } \\
\hline 376.0 & 2.946 & -2.612 & 2.965 & $11 \%$ & $1 \%$ & 226.2 & 1.772 & -1.606 & 1.785 & $9 \%$ & $1 \%$ \\
\hline 825.0 & 6.463 & -5.732 & 6.506 & $11 \%$ & $1 \%$ & 573.3 & 4.491 & -4.071 & 4.523 & $9 \%$ & $1 \%$ \\
\hline 1070.0 & 8.382 & -7.434 & 8.438 & $11 \%$ & $1 \%$ & 775.3 & 6.074 & -5.506 & 6.117 & $9 \%$ & $1 \%$ \\
\hline \multicolumn{6}{|c|}{ SA_long_4PB_20 } & \multicolumn{6}{|c|}{ SB_long_4PB_20 } \\
\hline 132.6 & 2.819 & -3.047 & 3.091 & $8 \%$ & $10 \%$ & 107.0 & 2.275 & -2.479 & 2.494 & $9 \%$ & $10 \%$ \\
\hline 275.7 & 5.861 & -6.335 & 6.426 & $8 \%$ & $10 \%$ & 228.0 & 4.847 & -5.282 & 5.315 & $9 \%$ & $10 \%$ \\
\hline 396.3 & 8.425 & -9.107 & 9.237 & $8 \%$ & $10 \%$ & 334.0 & 7.100 & -7.738 & 7.786 & $9 \%$ & $10 \%$ \\
\hline \multicolumn{6}{|c|}{ SA_long_4PB_30 } & \multicolumn{6}{|c|}{ SB_long_4PB_30 } \\
\hline 126.5 & 2.478 & -3.237 & 3.269 & $31 \%$ & $32 \%$ & 113.7 & 2.227 & -2.465 & 2.430 & $11 \%$ & $9 \%$ \\
\hline 245.5 & 4.808 & -6.281 & 6.345 & $31 \%$ & $32 \%$ & 231.5 & 4.534 & -5.018 & 4.948 & $11 \%$ & $9 \%$ \\
\hline 353.7 & 6.927 & -9.049 & 9.141 & $31 \%$ & $32 \%$ & 343.6 & 6.729 & -7.448 & 7.345 & $11 \%$ & $9 \%$ \\
\hline
\end{tabular}

Table 6: Analytical and FEA mid-span facing bending stress for the 4PB specimens.

The obtained results are in conformity presenting overall higher relative errors in the upper surface of the sandwich. The higher relative errors comparing the analytic with the FEA inf. are present in the SA_Short_3PB_20 reporting a 29\% and at the SA_Short_3PB_30 with 18\% of relative error on the 3PB specimens (Tab. 5) and in the SA_Long_4PB_30 with 32\% on the 4PB (Tab. 6). The 4PB specimens presents in the overall higher values of the FEA than the analytical contrary to the $3 \mathrm{~PB}$ specimens, indicating that the FEA is more conservative on the $3 \mathrm{~PB}$ specimens than on the $4 \mathrm{~PB}$. It should be also noted that the stresses obtained by the FEA sup. and FEA inf. differ at most 11\% on the SB_Short_4PB_20 specimen.

\section{Mid-span displacement behavior}

DIC2D mid-span vertical displacement analysis obtained from the experimental mid-point-load-displacement mechanical tests was compared to FEA and analytical results. The loads obtained previously (Tab. 5 and Tab. 6) from the three different mid-point crosshead displacement control: 1,2 and $3 \mathrm{~mm}$, were applied in all specimens and vertical displacements were obtained. Fig. 11 and Fig. 12 illustrates the typical vertical displacement behavior obtained from 3PB and 4PB tests, respectively. Also, a control image to assessment with null displacement control is displayed (Fig. 11(a) and Fig. 12 (a)). Because of the image repeatability, only one example of each load condition is exhibited.

A pink to red color spectrum represents the intensity of the vertical displacement. Red colors correspond to little displacement (for example on the support points) and the pink corresponds to the higher displacement (on the mid-point). For the purpose of better visualization, a scale is also plotted beneath the images, where it is shown the corresponding $v$ (vertical) displacement. As a result, foam cores show a rather uniform vertical deformation, i.e. in 4PB (Fig. 12) the displacement can be assumed almost steady between the two point-loading (steady purple color). 


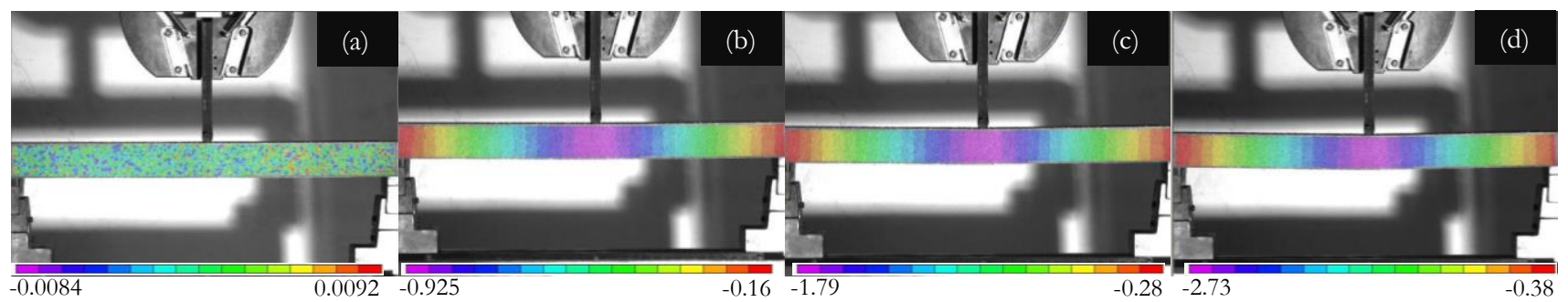

Figure 11: DIC analysis of mid-span displacement behavior of SB_long_4PB_30 tests with displacement control of: (a) Null; (b) 1 mm; (c) $2 \mathrm{~mm}$; (d) $3 \mathrm{~mm}$. (vertical displacement $v[\mathrm{~mm}]$ ).

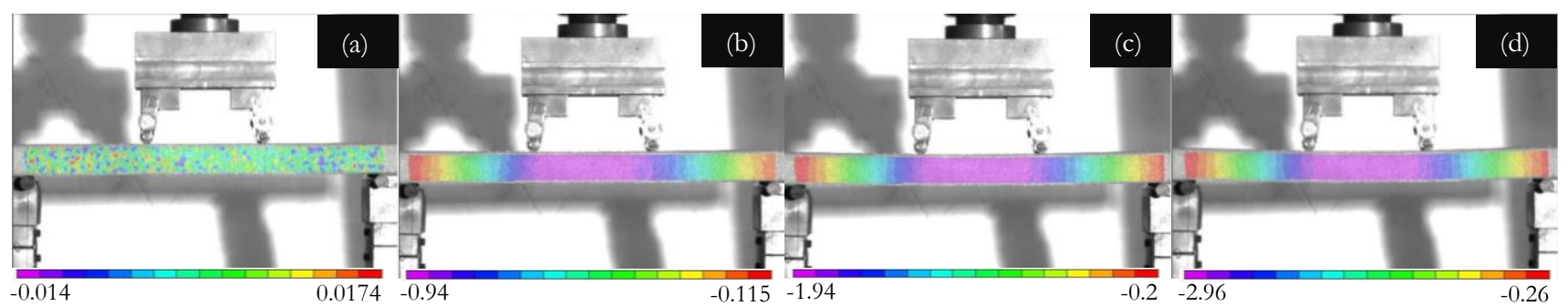

Figure 12: DIC analysis of mid-span displacement behavior of SB_long_4PB_20 tests with displacement control of: (a) Null; (b) 1 mm; (c) $2 \mathrm{~mm}$; (d) $3 \mathrm{~mm}$. (vertical displacement $v[\mathrm{~mm}]$ ).

Comparison between FEA and DIC displacement behavior plots under 3PB and 4PB tests with both situations: short- and long-beam are present in the examples of Fig. 13. Due to image repeatability, also a single example of each load condition is exhibited. In the FEA a purple to red color spectrum represents the intensity of the $v$ displacement where the purple corresponds to the higher displacement (on the mid-point). Qualitatively it is evident that both situations $(3 \mathrm{~PB} / 4 \mathrm{~PB}$ and short/long-beam) are in good agreement indicating that DIC analysis can capture vertical displacements properly. Obtained vertical displacements by analytical, DIC and FEA are present at Tab. 7 and Tab. 8 for 3PB and 4PB conditions, respectively and compared with the experimental results: 1, 2 and $3 \mathrm{~mm}$. Also, relative errors between: experimental/analytical; experimental/DIC and experimental/FEA are present. Analyzing the results, it is evident that for both $3 \mathrm{~PB}$ and $4 \mathrm{~PB}$ specimens, higher relative errors appears on both: 1 and $3 \mathrm{~mm}$. The reason for these can be due to the nonlinearity that may already occur in the $3 \mathrm{~mm}$ displacement, especially in the short-beams, proven by Fig. 7. In $1 \mathrm{~mm}$ displacement, the errors may be due to the initial required alignment of the load-displacement tests.

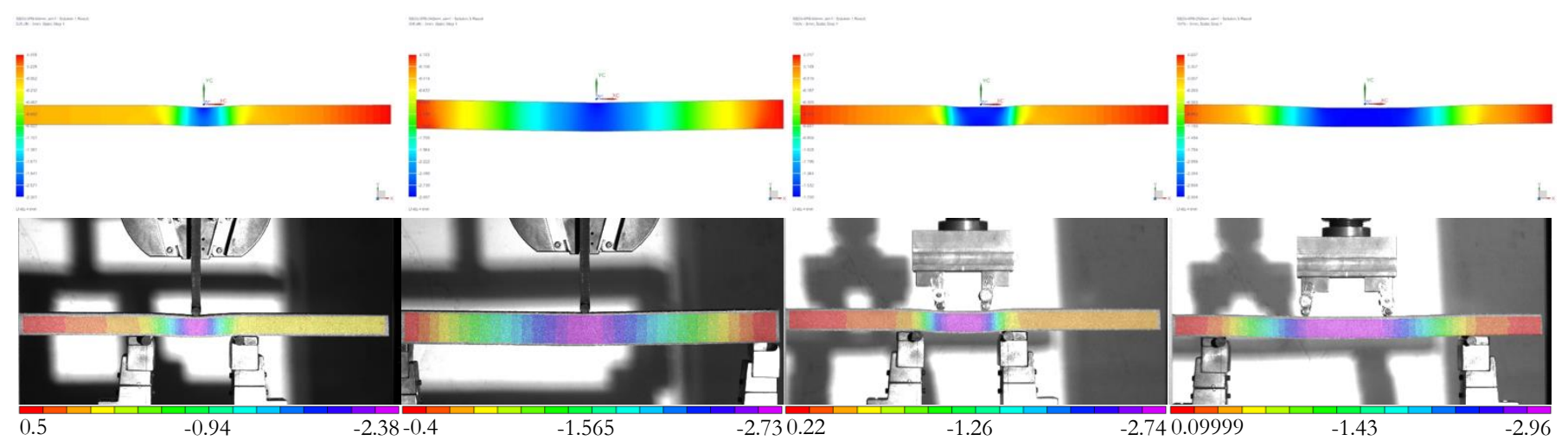

Figure 13: Mid-span $v$ displacement behavior under 3PB and 4PB specimens' with $3 \mathrm{~mm}$ of displacement control of FEA (upper images) and DIC technique (below images) of: (a) SB_short_3PB_20; (b) SB_long_3PB_30; (c) SB_short_4PB_20; (d) SB_long_4PB_20.

In the overall, the analytical, the DIC technique and the FEA were able to estimate the mid-point vertical deflection in both $3 \mathrm{~PB}$ and $4 \mathrm{~PB}$ sandwich specimens but showed considerable deviations in the case of short-beams, especially in the 4PB specimens, presenting higher relative errors. These higher relative errors are more evident for the 2 and $3 \mathrm{~mm}$ of experimental displacements and may be caused by the plastic region that some of these specimens arise. Also, SB specimens showed higher relative errors than the SA face specimens', indicating that BFRP skins are more locally capability of transferring deformation to the core by the constraints. 


\begin{tabular}{|c|c|c|c|c|c|c|c|c|c|c|c|}
\hline \multicolumn{3}{|c|}{$\begin{array}{l}\text { Mid-span vertical } \\
\text { displacement (mm) }\end{array}$} & \multirow{2}{*}{$\begin{array}{c}\text { Rel. Error } \\
\text { Exp./Ana. } \\
(\%)\end{array}$} & \multirow{2}{*}{$\begin{array}{c}\text { Rel. Error } \\
\text { Exp./DIC } \\
(\%)\end{array}$} & \multirow{2}{*}{$\begin{array}{c}\text { Rel. Error } \\
\text { Exp./FEA } \\
(\%)\end{array}$} & \multicolumn{3}{|c|}{$\begin{array}{l}\text { Mid-span vertical } \\
\text { displacement }(\mathrm{mm})\end{array}$} & \multirow{2}{*}{$\begin{array}{c}\text { Rel. Error } \\
\text { Exp./Ana. } \\
(\%)\end{array}$} & \multirow{2}{*}{$\begin{array}{l}\text { Rel. Error } \\
\text { Exp./DIC } \\
(\%)\end{array}$} & \multirow{2}{*}{$\begin{array}{c}\text { Rel. Error } \\
\text { Exp./FEA } \\
(\%)\end{array}$} \\
\hline Ana. & $D I C$ & FEA & & & & Ana. & DIC & FEA & & & \\
\hline \multicolumn{6}{|c|}{ SA_short_3PB_20 } & \multicolumn{6}{|c|}{ SB_short_3PB_20 } \\
\hline 1.3 & 0.8 & 0.9 & $25 \%$ & $22 \%$ & $11 \%$ & 0.9 & 0.8 & 0.9 & $11 \%$ & $19 \%$ & $9 \%$ \\
\hline 2.5 & 1.7 & 1.8 & $23 \%$ & $17 \%$ & $12 \%$ & 1.9 & 1.6 & 1.9 & $7 \%$ & $19 \%$ & $5 \%$ \\
\hline 2.8 & 2.3 & 2.0 & $5 \%$ & $23 \%$ & $33 \%$ & 2.3 & 2.4 & 2.3 & $25 \%$ & $21 \%$ & $23 \%$ \\
\hline \multicolumn{6}{|c|}{ SA_short_3PB_30 } & \multicolumn{6}{|c|}{ SB_short_3PB_30 } \\
\hline 1.1 & 0.9 & 1.0 & $7 \%$ & $12 \%$ & $1 \%$ & 0.8 & 0.7 & 0.9 & $19 \%$ & $30 \%$ & $6 \%$ \\
\hline 2.1 & 1.7 & 1.9 & $3 \%$ & $14 \%$ & $3 \%$ & 1.7 & 1.5 & 2.0 & $13 \%$ & $23 \%$ & $0 \%$ \\
\hline 2.7 & 2.4 & 2.5 & $11 \%$ & $19 \%$ & $16 \%$ & 2.3 & 2.1 & 2.6 & $24 \%$ & $32 \%$ & $12 \%$ \\
\hline \multicolumn{6}{|c|}{ SA_long_3PB_20 } & \multicolumn{6}{|c|}{ SB_long_3PB_20 } \\
\hline 0.9 & 0.9 & 0.9 & $6 \%$ & $11 \%$ & $10 \%$ & 0.9 & 1.3 & 1.0 & $5 \%$ & $26 \%$ & $2 \%$ \\
\hline 2.1 & 1.8 & 2.0 & $7 \%$ & $9 \%$ & $2 \%$ & 2.0 & 2.2 & 2.1 & $1 \%$ & $10 \%$ & $4 \%$ \\
\hline 3.3 & 2.8 & 3.2 & $10 \%$ & $7 \%$ & $6 \%$ & 3.1 & 3.2 & 3.2 & $4 \%$ & $6 \%$ & $7 \%$ \\
\hline \multicolumn{6}{|c|}{ SA_long_3PB_30 } & \multicolumn{6}{|c|}{ SB_long_3PB_30 } \\
\hline 0.9 & 0.8 & 0.9 & $12 \%$ & $17 \%$ & $10 \%$ & 0.8 & 0.9 & 0.9 & $24 \%$ & $8 \%$ & $12 \%$ \\
\hline 1.8 & 1.8 & 1.8 & $11 \%$ & $10 \%$ & $9 \%$ & 1.7 & 1.8 & 1.9 & $17 \%$ & $11 \%$ & $4 \%$ \\
\hline 2.7 & 2.8 & 2.8 & $10 \%$ & $8 \%$ & $8 \%$ & 2.6 & 2.7 & 3.0 & $13 \%$ & $9 \%$ & $0 \%$ \\
\hline
\end{tabular}

Table 7: Analytical, DIC and FEA mid-span vertical displacement for the 3PB specimens.

\begin{tabular}{|c|c|c|c|c|c|c|c|c|c|c|c|}
\hline \multicolumn{3}{|c|}{$\begin{array}{l}\text { Mid-span vertical } \\
\text { displacement }(\mathrm{mm})\end{array}$} & \multirow{2}{*}{$\begin{array}{c}\text { Rel. Error } \\
\text { Exp./Ana. } \\
(\%)\end{array}$} & \multirow{2}{*}{$\begin{array}{c}\text { Rel. Error } \\
\text { Exp./DIC } \\
(\%)\end{array}$} & \multirow{2}{*}{$\begin{array}{c}\text { Rel. Error } \\
\text { Exp./FEA } \\
(\%)\end{array}$} & \multicolumn{3}{|c|}{$\begin{array}{l}\text { Mid-span vertical } \\
\text { displacement }(\mathrm{mm})\end{array}$} & \multirow{2}{*}{$\begin{array}{c}\text { Rel. Error } \\
\text { Exp./Ana. } \\
(\%)\end{array}$} & \multirow{2}{*}{$\begin{array}{c}\text { Rel. Error } \\
\text { Exp./DIC } \\
(\%)\end{array}$} & \multirow{2}{*}{$\begin{array}{c}\text { Rel. Error } \\
\text { Exp./FE } A \\
(\%)\end{array}$} \\
\hline Ana. & DIC & FEA & & & & Ana. & $D I C$ & $F E A$ & & & \\
\hline \multicolumn{6}{|c|}{ SA_short_4PB_20 } & \multicolumn{6}{|c|}{ SB_short_4PB_20 } \\
\hline 1.1 & 1.0 & 0.9 & $8 \%$ & $4 \%$ & $10 \%$ & 0.9 & 0.9 & 0.9 & $11 \%$ & $11 \%$ & $8 \%$ \\
\hline 2.0 & 2.1 & 1.7 & $0 \%$ & $4 \%$ & $17 \%$ & 1.4 & 1.8 & 1.4 & $31 \%$ & $11 \%$ & $29 \%$ \\
\hline 2.3 & 3.0 & 1.9 & $23 \%$ & $0 \%$ & $37 \%$ & 1.6 & 2.7 & 1.7 & $46 \%$ & $9 \%$ & $44 \%$ \\
\hline \multicolumn{6}{|c|}{ SA_short_4PB_30 } & \multicolumn{6}{|c|}{ SB_short_4PB_30 } \\
\hline 0.8 & 1.0 & 0.8 & $17 \%$ & $3 \%$ & $16 \%$ & 0.5 & 0.8 & 0.6 & $49 \%$ & $18 \%$ & $42 \%$ \\
\hline 1.8 & 2.1 & 1.8 & $9 \%$ & $2 \%$ & $8 \%$ & 1.3 & 1.7 & 1.5 & $35 \%$ & $17 \%$ & $27 \%$ \\
\hline 2.4 & 2.9 & 2.4 & $21 \%$ & $2 \%$ & $21 \%$ & 1.8 & 2.5 & 2.0 & $42 \%$ & $17 \%$ & $34 \%$ \\
\hline \multicolumn{6}{|c|}{$S A \_l o n g \_4 P B \_20$} & \multicolumn{6}{|c|}{ SB_long_4PB_20 } \\
\hline 0.8 & 1.1 & 1.0 & $20 \%$ & $5 \%$ & $2 \%$ & 0.7 & 0.9 & 1.0 & $28 \%$ & $6 \%$ & $4 \%$ \\
\hline 1.7 & 2.1 & 2.1 & $17 \%$ & $6 \%$ & $7 \%$ & 1.5 & 1.9 & 2.0 & $23 \%$ & $3 \%$ & $2 \%$ \\
\hline 2.4 & 3.2 & 3.1 & $20 \%$ & $6 \%$ & $2 \%$ & 2.3 & 3.0 & 3.0 & $25 \%$ & $1 \%$ & $0 \%$ \\
\hline \multicolumn{6}{|c|}{$S A \_l o n g \_4 P B \_30$} & \multicolumn{6}{|c|}{ SB_long_4PB_30 } \\
\hline 0.7 & 1.0 & 1.0 & $28 \%$ & $3 \%$ & $1 \%$ & 0.7 & 1.0 & 1.0 & $26 \%$ & $5 \%$ & $3 \%$ \\
\hline 1.4 & 1.1 & 2.0 & $30 \%$ & $46 \%$ & $2 \%$ & 1.5 & 1.1 & 2.1 & $24 \%$ & $44 \%$ & $5 \%$ \\
\hline 2.0 & 1.8 & 2.8 & $33 \%$ & $40 \%$ & $6 \%$ & 2.2 & 1.8 & 3.1 & $25 \%$ & $40 \%$ & $4 \%$ \\
\hline
\end{tabular}

Table 8: Analytical, DIC and FEA mid-span vertical displacement for the 4PB specimens. 


\section{Mid-span strain-fields behavior}

Strain-fields behavior was also acquired using DIC and FEA for the 1, 2 and $3 \mathrm{~mm}$ of displacement control. In Fig. 14 it is showed the increase of the shear effect with the increase of the load obtained through DIC technique. A pink to red color spectrum represents the intensity of the $\varepsilon_{\mathrm{xx}}$ strains. Pink color corresponds to negative strains (for example in the region between the loading points) and the red corresponds to the positive strains (in the alignment of the loading points).

The main difference between the two face materials: $S A$ and $S B$, is present in the vertical-aligned region with the loading and contact points. In the $S A$ specimens (Fig. 14 (a), (b) and (c)), it is visible that the sandwich is subjected to higher strains in the opposite side of the applied loads compared with the $S B$ (Fig. 14 (d), (e) and (f)), that shows different comportment, presenting higher strains adjacent to constraints. Juntikka et al. [28] showed that sandwiches structures are in general sensitive to localized loads. An applied compressive load will cause the exposed face sheet to deform locally and, as the load increases, indentation will eventually occur induced by core compression failure, so the pressure distribution under applied load depends on the bending stiffness of the face sheet. When the face stiffness is low, the contact load is virtually transmitted straight through the face sheet to the underlying core, while for rigid skins the load is spread out, affecting a larger area of the underlying core. This behavior is shown on BFRP face specimens less stiffness presenting a more localized deformation in the location of the loading/support (areas in red) than the specimens with aluminum faces.
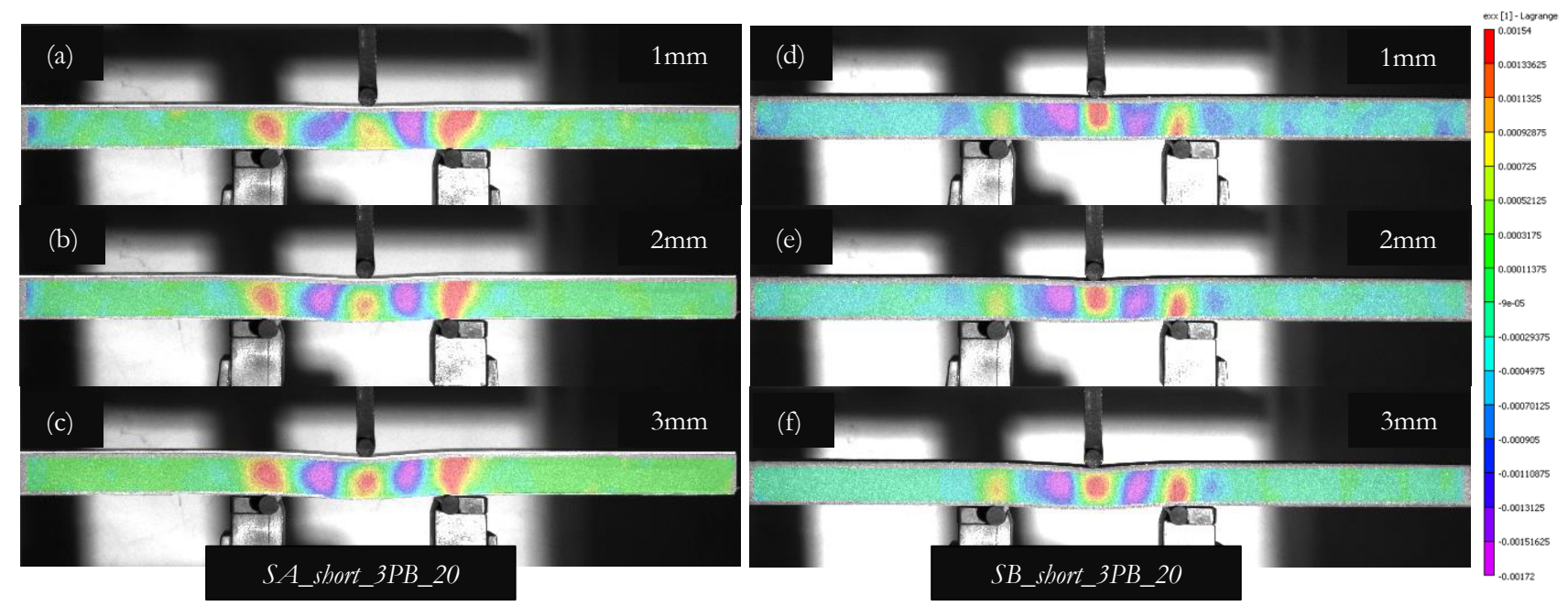

Figure 14: Mid-span VIC $\varepsilon_{\mathrm{xx}}$ contour behavior of: $S A$ face sandwich's with (a) $1 \mathrm{~mm}$; (b) $2 \mathrm{~mm}$; (c) 3 mm; and $S B$ face sandwich's with (d) $1 \mathrm{~mm}$; (e) $2 \mathrm{~mm}$; (f) $3 \mathrm{~mm}$.

Furthermore, $\varepsilon_{\mathrm{xx}}$ strain-fields behavior of DIC technique was qualitatively compared with the FEA likewise was the vertical displacements. This way results obtained by these two methods for 3PB and 4PB are plotted on Fig. 15 and Fig. 16 respectively for both $S A$ and $S B$ specimens. Due to image repeatability, only images of the $3 \mathrm{~mm}$ of displacement control are illustrated.

Fig. 15 (a), Fig. 15 (b), Fig. 16 (a) and Fig. 16 (b) are relative to short specimens and Fig. 15 (c), Fig. 15 (d), Fig. 16 (c) and Fig. 16 (d) for longer ones. Each pair of figures compares $S A$ with $S B$ face materials. In all tested specimens by FEA and DIC technique, strain image results are in good conformity. The $S B$ skin sandwich is extremely locally deformable resulting in a redistribution of the strains nearby the applied load region contrary to the $S A$ specimens.

$\varepsilon_{\mathrm{xx}}$ distribution along the normalized mid-span-length along the thickness of the specimens with $3 \mathrm{~mm}$ of displacement control under $3 \mathrm{~PB}$ and $4 \mathrm{~PB}$ tests for short and long-beams on $S A$ and $S B$ specimens respectively are shown in Fig. 17 and Fig. 18. Due to image repeatability, only images of the $3 \mathrm{~mm}$ of displacement control are illustrated.

Fig. 17 (a) and Fig. 17 (b) plots strain distribution of sandwiches with aluminum skins with short and long beams respectively. Fig. 18 (a) and Fig. 18 (b) plots strain distribution of sandwiches with BFRP skins also for the short and long beams respectively. Experimental strains using strain-gages glued on the top and bottom faces (in the 4PB specimens) and to the bottom skin (in the 3PB) were also measured and are present in Fig. 17 and Fig. 18 with a red round (3PB) and black squares (4PB) markers. 


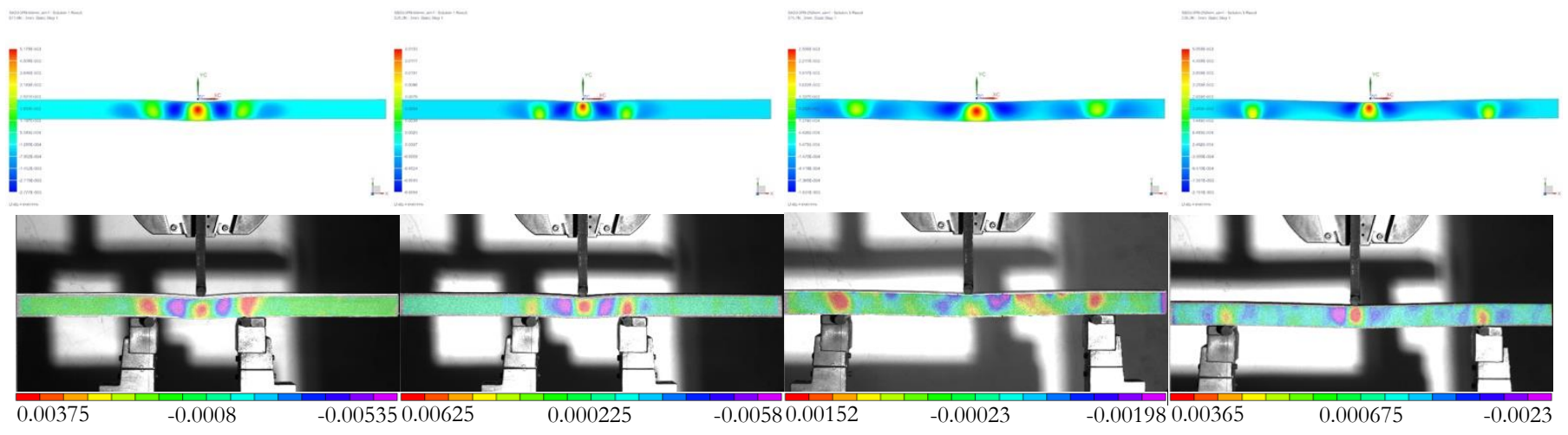

Figure 15: Mid-span $\varepsilon_{\mathrm{xx}}$ contour behavior under 3PB specimens' with $3 \mathrm{~mm}$ of displacement control of FEA (upper images) and DIC technique (below images) from: (a) SA_short_3PB_20; (b) SB_short_3PB_20; (c) SA_long_3PB_20; (d) SB_long_3PB_20.

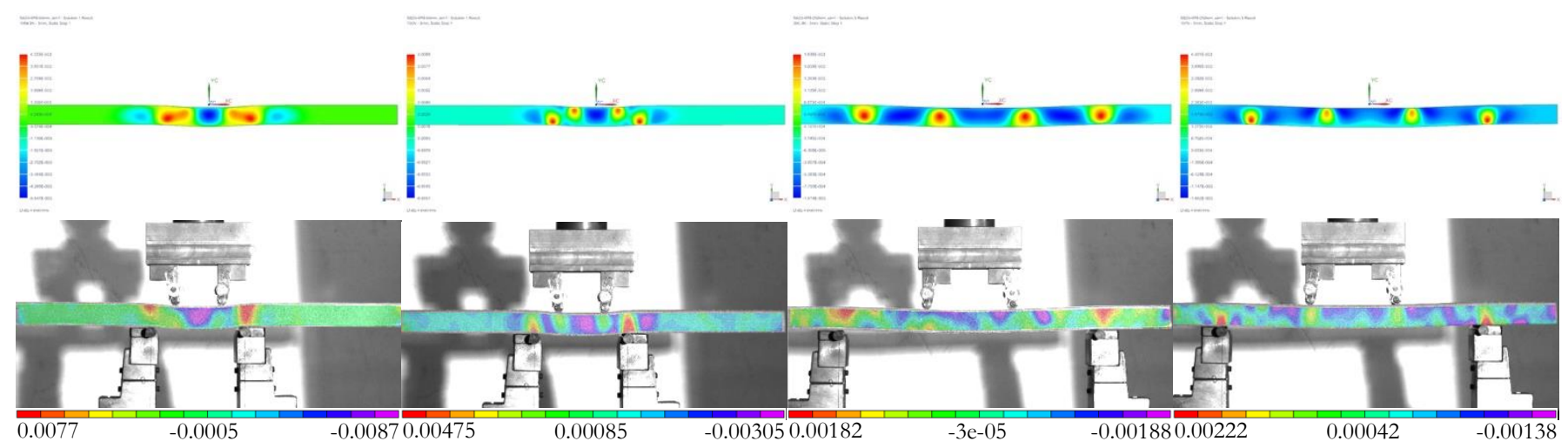

Figure 16: Mid-span $\varepsilon_{\mathrm{xx}}$ contour behavior under 3PB specimens' with $3 \mathrm{~mm}$ of displacement control of FEA (upper images) and DIC technique (below images) from: (a) $S A \_s h o r t \_4 P B \_20$; (b) (b) $S B \_s h o r t 4 P B \_20$; (c) $S A \_l o n g \_4 P B \_20$; (d) SB_long_4PB_20.

\section{$\varepsilon_{\mathrm{xx}}[\mathrm{mm} / \mathbf{m m}]$}

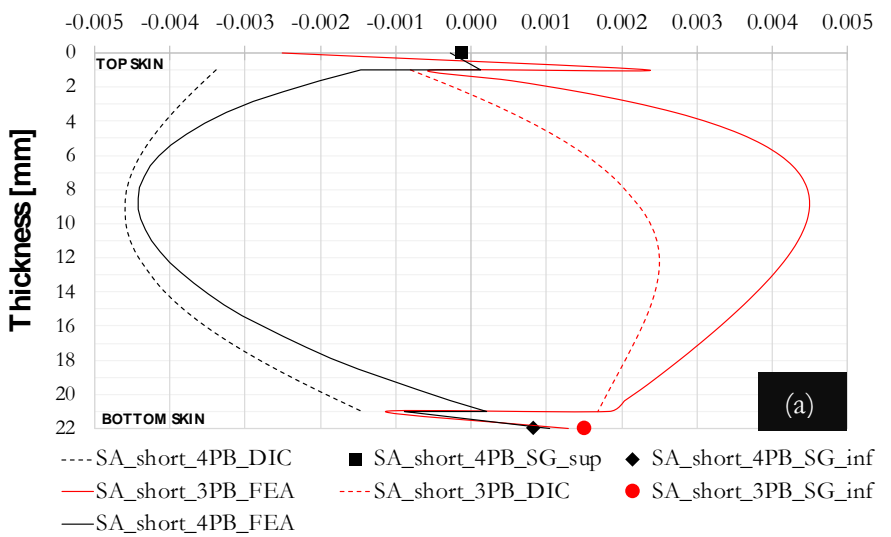

$\varepsilon_{\mathrm{xx}}[\mathrm{mm} / \mathrm{mm}]$

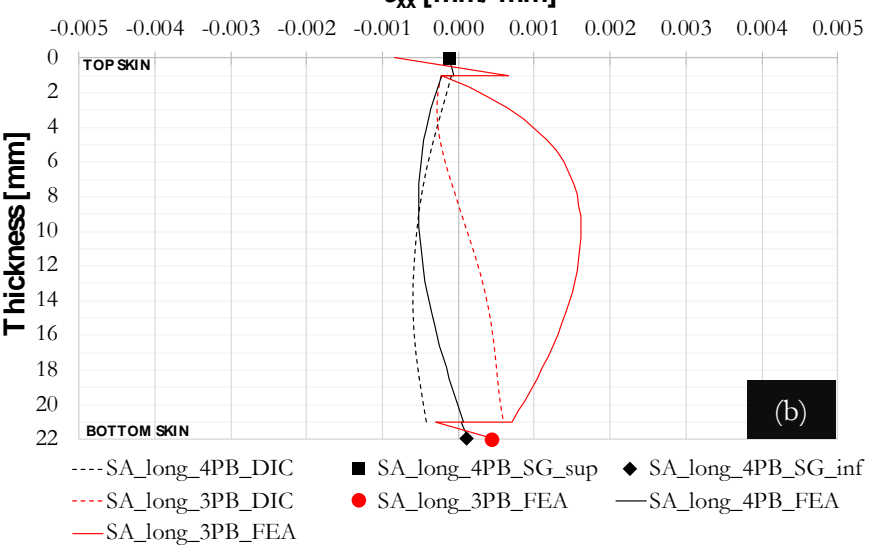

Figure 17: Mid-span $\varepsilon_{\mathrm{xx}}$ distribution for $3 \mathrm{~mm}$ of displacement control of FEA (continuous lines __) and DIC technique (dashed lines _ - - ) under 3PB (red lines) and 4PB (black lines) of: (a) $S A \_$short; (b) $S A \_l o n g$ (SG_sup and $S G \_$inf - refers to strain-gages in the upper and bottom faces).

It is clear that for both face materials $(S A$ and $S B)$ the $3 \mathrm{~PB}$ tests presents a mostly positive $\varepsilon_{\mathrm{xx}}$ distribution along thickness while the 4PB exhibits negative strains, due to shear effects suggesting compression zone. Likewise, 4PB SB_long specimens (Fig. 18 (b)) exhibit an almost linear distribution, with negative strains in the top and positive strains in the bottom, showing that it is no longer influenced by the loading/support pressure zones. This phenomenon is corroborated by Fig. 16 (d) where the color pattern shows the positive and negative strains. Therefore, it is evident that specimens with BFRP faces 
presents a more localized deformation nearby the applied load region than the specimens of aluminum faces, confirmed by the higher strains observed near the top face.
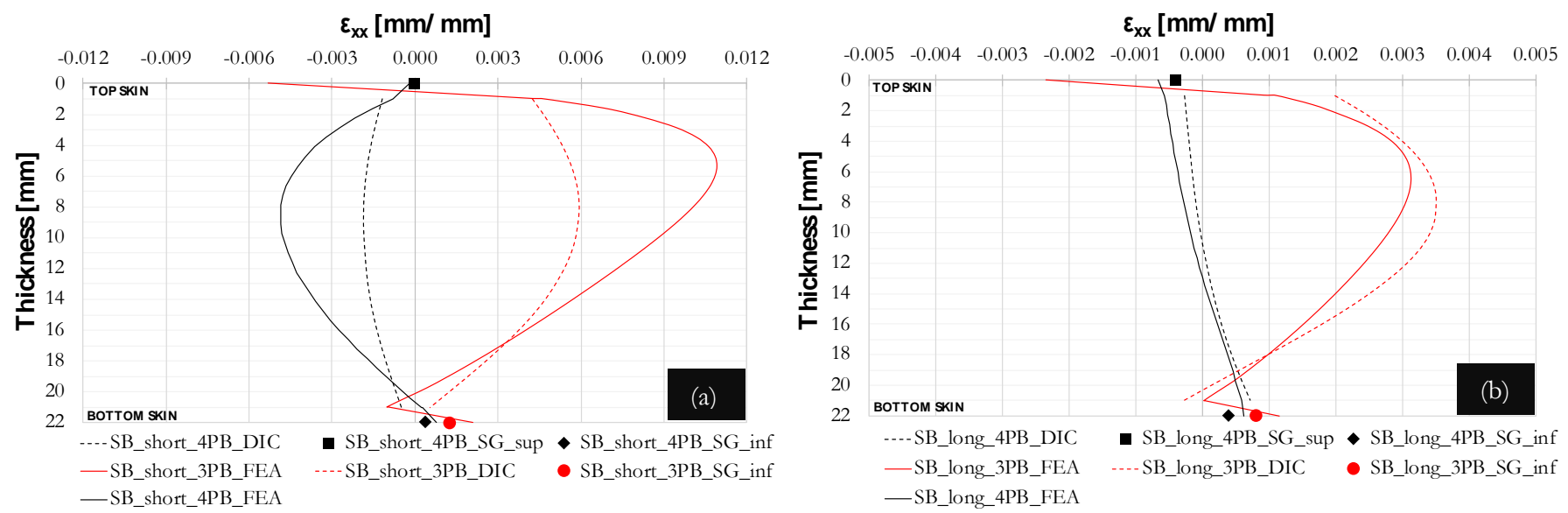

Figure 18: Mid-span $\varepsilon_{\mathrm{xx}}$ distribution for $3 \mathrm{~mm}$ of displacement control of FEA (continuous lines __) and DIC technique (dashed lines _-_- ) under 3PB (red lines) and 4PB (black lines) of: (a) $S B \_s h o r t$, (b) $S B \_l o n g ~\left(S G \_s u p\right.$ and $S G \_$inf - refers to strain-gages in the upper and bottom faces).

Strain gages' results are in very good conformity with the FEA, however when compared with the DIC results, it is evident that this technique was not allowed to evaluate the face region of the sandwich composites, showing a gap on these region presented also in Fig. 15 and Fig. 16 (DIC images) and evidenced by Fig. 17 and Fig. 18 (plot results). This way the straingage results shows that they are a complementary analysis to the DIC technique, since the DIC2D technique capture the strains in the core of the sandwich and the strain-gages captures the strains in the skins.

The use of materials with different mechanical properties on the skin and core, causes a discontinuity in the deformed planes face-to-face at the interface. This effect is known as "zig-zag" and is more evident on specimens with aluminum faces (Fig. 17). Also, the FEA results of the $S A$ specimens shows a large discontinuity in the $\varepsilon_{\mathrm{xx}}$ distribution in the core-face interface revealing an adhesive failure which is proven by Fig. 9 and Fig. 10 where this fact is observable.

\section{CONCLUSIONS}

3 $\mathrm{PB}$ and $4 \mathrm{~PB}$ tests of sandwich beams with polyurethane core and two different skin materials: aluminum and BFRP, have been performed to estimate the behavior of short- and long-beams. The study involved experimental investigation using digital image correlation (DIC) and strain gages. Finite element analysis (FEA) was implemented to obtain the stress-strain-fields of face-interface-core materials under bending tests. Strain-gages were used in order to measure strains in the top and bottom faces of the sandwiches and evaluate the results with the FEA and DIC analysis. Also, flexural failure behavior of sandwiches was studied.

Mid-span displacement behavior was also analyzed by means of analytical, DIC and FEA to estimate the mid-point vertical deflection in both $3 \mathrm{~PB}$ and $4 \mathrm{~PB}$ sandwich specimens. These analyses showed that:

- plot contours were able to estimate displacements by means of DIC and FEA;

- however, plot contours showed considerable deviations in mid-span-displacement results in the case of shortbeams, especially in the $4 \mathrm{~PB}$ specimens, presenting higher relative errors.

- basalt fiber (BFRP) showed higher relative errors than the aluminum face specimens', indicating that BFRP skins are more locally capable of transferring deformation to the core by the constraints.

The strain contours obtained from FEA and DIC have been compared and showed good agreement and demonstrated that:

- BFRP sandwiches are more locally deformable by the constrains than the aluminum specimens.

- short beams under $4 \mathrm{~PB}$ present compression strains at mid-span length due the shear effects for both specimens (aluminum and BFRP).

Strain-gages results showed that:

- are a complementary analysis to DIC analysis as this method cannot evaluate the face region of the sandwich composites. 
- $\quad$ are in conformity with the FEA results.

BFRP sandwiches showed higher flexibility and higher capacity of absorption energy than the aluminum specimens however the higher flexibility of the BFRP specimens causes higher prospect of core shear failure.

The "zig-zag" effect, due to the use of different materials on the face and core, is evident on the specimens with aluminum faces. The DIC technique overcame the challenge in the deformation measurements of the $3 \mathrm{~PB}$ and $4 \mathrm{~PB}$ tests, since through-the-thickness strain distributions could be obtained from the full-field strain evaluation.

Very important results are presented in this work regarding the full-strain fields of short and long sandwich beams under $3 \mathrm{~PB}$ and $4 \mathrm{~PB}$.

\section{ACKNOWLEDGEMENTS}

his work was supported by FCT, through IDMEC, under LAETA, project UID/EMS/50022/2019.

\section{REFERENCES}

[1] Davies, J.M., (2014). Lightweight Sandwich Construction. Blackwell Science, Oxford.

[2] Martins, R., Reis, L., Marat-Mendes, R., (2016). Finite element prediction of stress-strain fields on sandwich composites. Procedia Structural Integrity. 1, pp. 066-073.

[3] Fiore, V., Scalici, T., Di Bella, G., Valenza, A. (2015). A review on basalt fibre and its composites. Composites Part B: Engineering. 74, pp. 74-94.

[4] Torres, J.P., Hoto, R., Andrés, J., Garcia-Manrique, J.A. (2013). Manufacture of Green-Composite Sandwich Structures with Basalt Fiber and Bioepoxy Resin. Advances in Materials Science and Engineering. 2013, 9 pages.

[5] Zenkert, D. (1997). An Introduction to Sandwich Construction, Emmas Publishing, UK.

[6] ASTM C273-00e1 (2000). Standard Test Method for Shear Properties of Sandwich Core Materials. ASTM International, West Conshohocken, PA.

[7] ASTM C393 / C393M-16 (2000). Standard Test Method for Core Shear Properties of Sandwich Constructions by Beam Flexure. ASTM International, West Conshohocken, PA.

[8] O'Connor, D.J. (1984). An Evaluation of Test Methods for Shear Modulus of Sandwich Cores. The International Journal of Cement Composites and Lightweight Concrete. 6(1), pp. 3-12.

[9] Allen, H.G. (1969). Analysis and Design of Structural Sandwich Panels. Pergamon Press, London, UK.

[10] de Freitas, S.T., Kolstein, H., \& Bijlaard, F. (2011). Sandwich system for renovation of orthotropic steel bridge decks. Journal of Sandwich Structures \& Materials. 13(3), pp. 279-301.

[11] Reis, L., Carvalho, P., Alves, C., Freitas, M., (2010). Mechanical Behaviour of Sandwich Beams Manufactured with Glass or Jute Fiber in Facings and Cork Agglomerates as Core. Materials Science Forum. 245, pp. 636-637.

[12] Reis, L., Silva, A., (2009). Mechanical Behavior of Sandwich Structures using Natural Cork Agglomerates as Core Materials. Journal of Sandwich Structures and Materials, 11:6, pp. 487-500.

[13] Sutton, M.A., Orteu, J.J., Schreier, H., (2009). Image correlation for shape motion and deformation measurements: basic concepts, theory and applications. New York: Springer.

[14] Pierron, F., Grédiac, M., (2012). The virtual fields method: extracting constitutive parameters from full-field deformation measurements. New York: Springer.

[15] Cintrón, R., Saouma, V. (2008). Strain measurements with the digital image correlation system vic-2d, report CU-NEES08-06. Tech. rep., NEES at CU Boulder.

[16] Yang, L., Smith, L., Gothekar, A. and Chen, X. (2010). Measure Strain Distribution Using Digital Image Correlation (DIC) for Tensile Tests, Oakland.

[17] Fergusson, A.D., Puri, A., Morris, A., Dear, J. (2006). Flexural Testing of Composite Sandwich Structures with Digital Speckle Photogrammetry. Applied Mechanics and Materials. 5-6, pp. 135-144.

[18] ASTM C365 / C365M-16 (2016). Standard Test Method for Flatwise Compressive Properties of Sandwich Cores, ASTM International, West Conshohocken, PA.

[19]ASTM C274-99 (1999). Standard Terminology of Structural Sandwich Constructions, ASTM International, West Conshohocken, PA, 1999. 
[20] ASTM D7249 / D7249M-12e1 (2012). Standard Test Method for Facesheet Properties of Sandwich Constructions by Long Beam Flexure, ASTM International, West Conshohocken, PA.

[21] Sutton, M.A., Orteu, J.J., Schereier, H. (2009). Image Correlation for Shape, Motion and Deformation Measurements: Basic Concepts, Theory and Applications. Springer Publishing Company, Incorporated.

[22] Correlated Solutions, Inc., (2017). Digital Image Correlation. Available at: http://www.correlatedsolutions.com.

[23] Vic-2D Reference Manual (2009). Correlated Solutions. http://www.correlatedsolutions.com/installs/Vic-2D-2009Manual.pdf.

[24] Sun, E.Q. (2006). Shear Locking and Hourglassing in MSC Nastran, ABAQUS, and ANSYS. MSC Softw. Users Conf., pp. 1-9.

[25] Jensen, A., Laird, G., BheemReddy, V. (2015). Composite Laminate Modeling: Handbook for Femap, NX Nastran and LS-DYNA Users. Predictive Engineering White Paper, pp. 106.

[26] Goncharov, P., Artamonov, I., Khalitov, T. (2014). Engineering Analysis with NX Advanced Simulation. Lulu Publishing Services.

[27] Jensen, A. (2010). Linear Contact Analysis: Demystified. Predictive Engineering White Paper, pp. 1- 21.

[28] Juntikka, R., Hallstrom, S. (2007). Shear Characterization of Sandwich Core Materials Using Four-Point Bending. Journal of Sandwich Structures and Materials, 9(1), pp. 67-94. 